\title{
Nuclear accumulation of cyclin D1 during $S$ phase inhibits Cul4-dependent Cdt1 proteolysis and triggers p53-dependent DNA rereplication
}

\author{
Priya Aggarwal, ${ }^{1}$ Matthew D. Lessie, ${ }^{1}$ Douglas I. Lin,,${ }^{1,2}$ Laura Pontano, ${ }^{1,2}$ Andrew B. Gladden, ${ }^{1}$ \\ Beth Nuskey, ${ }^{3}$ Ami Goradia, ${ }^{4}$ Mariusz A. Wasik, ${ }^{4}$ Andres J.P. Klein-Szanto, ${ }^{5}$ Anil K. Rustgi, ${ }^{6}$ \\ Craig H. Bassing, ${ }^{1,2,3,4}$ and J. Alan Diehl ${ }^{1,2,7}$ \\ ${ }^{1}$ The Abramson Family Cancer Research Institute, University of Pennsylvania, Philadelphia, Pennsylvania 19104, USA; \\ ${ }^{2}$ Department of Cancer Biology, University of Pennsylvania, Philadelphia, Pennsylvania 19104, USA; ${ }^{3} \mathrm{Children}^{\prime}$ s Hospital of \\ Philadelphia, Philadelphia, Pennsylvania 19104, USA; ${ }^{4}$ Department of Pathology and Laboratory Medicine, University of \\ Pennsylvania, Philadelphia, Pennsylvania 19104, USA; ${ }^{5}$ Fox Chase Cancer Center, Philadelphia, Pennsylvania 19111, USA; \\ ${ }^{6}$ Department of Medicine, University of Pennsylvania, Philadelphia, Pennsylvania 19104, USA
}

\begin{abstract}
Deregulation of cyclin D1 occurs in numerous human cancers through mutations, alternative splicing, and gene amplification. Although cancer-derived cyclin D1 mutants are potent oncogenes in vitro and in vivo, the mechanisms whereby they contribute to neoplasia are poorly understood. We now provide evidence derived from both mouse models and human cancer-derived cells revealing that nuclear accumulation of catalytically active mutant cyclin D1/CDK4 complexes triggers DNA rereplication, resulting from Cdt1 stabilization, which in turn triggers the DNA damage checkpoint and p53-dependent apoptosis. Loss of p53 through mutations or targeted deletion results in increased genomic instability and neoplastic growth. Collectively, the data presented reveal mechanistic insights into how uncoupling of critical cell cycle regulatory events will perturb DNA replication fidelity, thereby contributing to neoplastic transformation.
\end{abstract}

[Keywords: Cdt1; Cul4; cyclin D1T286A; cyclin D1P287A; rereplication; p53; genomic instability]

Supplemental material is available at http://www.genesdev.org.

Received June 22, 2007; revised version accepted September 21, 2007.

Dysregulation of the pathways that contribute to the normal integration of growth factor signaling and cell division lies at the heart of neoplastic growth. Cyclin D expression, accumulation, and its ability to associate with catalytic partners CDK4/6 are regulated by mitogenic signaling, allowing D cyclins to serve as mediators of growth factor signaling and cell cycle progression (Gladden and Diehl 2005). Cyclin D1 gene expression depends on activation of the small GTP-binding protein, Ras (Marshall 1999). Ras activates canonical MAP kinase signaling (RAF-MEK-ERK); activation of this pathway is both necessary and sufficient for cyclin D1 expression and association with CDK4 (Albanese et al. 1995; Lavoie et al. 1996; Aktas et al. 1997; Cheng et al. 1998). Ras also contributes to the accumulation of the cyclin D1 protein, via a pathway involving PI3K and Akt, which attenuates the GSK3 $\beta$ kinase (Franke et al. 1995, 1997);

${ }^{7}$ Corresponding author.

E-MAIL adiehl@mail.med.upenn.edu; FAX (215) 746-5511.

Article is online at http://www.genesdev.org/cgi/doi/10.1101/gad.1586007.
GSK3 $\beta$-dependent phosphorylation of cyclin D1 on Thr286 promotes cyclin D1 proteolysis (Diehl et al. 1998). Cyclin D1 subcellular localization is also regulated during cell cycle progression. Phosphorylation of cyclin D1 on Thr286 at the G1/S-phase boundary promotes CRM1-dependent nuclear export (Alt et al. 2000). Thus, Thr286 phosphorylation coordinates two critical regulatory events. First, it removes the cyclin D1 kinase from the nucleus during $S$ phase, thereby sequestering it from potential substrates. Second, ubiquitin-mediated destruction of cyclin D1 requires cytoplasmic localization, as the D1 E3 ligase is restricted to the cytoplasm (Lin et al. 2006).

Cyclin D1 overexpression occurs in carcinomas of the esophagus, head and neck, breast, and colon, as well as certain B-cell lymphomas (Bartkova et al. 1994a,b, 1995; Gillett et al. 1994; Herman et al. 1995; Barnes and Gillett 1998; Hibberts et al. 1999; Hosokawa et al. 1999; BaniHani et al. 2000; Hemmer et al. 2001; Ikeguchi et al. 2001; Jin et al. 2001); overexpression can result from gene amplification, chromosomal translocation, or protein stabilization (Sherr 1996). Strikingly, unlike strong 
oncogenes such as Ras, overexpression of cyclin D1 alone cannot transform immortalized murine fibroblasts in vitro (Alt et al. 2000). Furthermore, while overexpression of cyclin D1 is considered the initial genetic trigger in mantle cell lymphoma, targeted expression of wildtype cyclin D1 in lymphoid cells does not result in a tumor-prone phenotype (Bodrug et al. 1994; Lovec et al. 1994), thereby challenging the notion that cyclin D1 is an oncogene. In contrast, recent work has revealed that inhibition of cyclin D1 nuclear export during S phase unmasks its neoplastic potential (Alt et al. 2000). Constitutively nuclear cyclin D1 mutants are found in carcinomas of the esophagus, and induce cell transformation in vitro (Benzeno et al. 2006) and promote tumorigenesis in transgenic mice (Gladden et al. 2006). These results imply that nuclear retention of cyclin D1 during $S$ phase is a tumor-initiating event.

Neoplastic transformation is closely associated with genomic instability. Genomic integrity is monitored by checkpoints designed to trigger cell cycle arrest or apoptosis (Kastan and Bartek 2004; Hoglund 2006). A common outcome of genomic instability in tumors is aneuploidy and chromosomal translocations or deletions. Aneuploidy commonly results from missegregation of chromosomal complements during mitosis or rereplication of cellular DNA (Rajagopalan and Lengauer 2004), while translocations and deletions result from errors in the repair of DNA double-strand breaks (DSBs). Such defects might occur as a result of the inactivation of checkpoints that generally sense DNA damage, replication stress, or mitotic failure. Recent work revealed induction of DNA damage in premalignant tissue (Bartkova et al. 2005; Gorgoulis et al. 2005), suggesting a mechanism whereby oncogenic stress in nonmalignant cells may provide selective pressure to delete p53 and promote tumorigenesis.
The increased oncogenicity of constitutively nuclear cyclin D1T286A relative to wild-type cyclin D1 suggests that nuclear retention during $\mathrm{S}$ phase is gain of function. To elucidate mechanisms of neoplastic transformation, we characterized the molecular mechanisms of lymphoma development in mice harboring a lymphoidspecific cyclin D1T286A transgene (Gladden et al. 2006). Analysis reveals that nuclear accumulation of D1T286A/CDK4 during S phase triggers DNA damage and activation of the ATM-CHK2-p53 checkpoint pathway. Activation of p53 is associated with D1T286A-dependent stabilization of Cdt1, which in turn promotes relicensing of replication origins during $S$ phase and ensuing DNA rereplication. Tumor development in D1T286A transgenic mice occurs upon inactivation of p53 and can be significantly accelerated by targeted deletion of p53. Our data demonstrate that inappropriate localization of active cyclin D1/CDK4 complexes interferes with the temporal regulation of DNA replication and thereby contributes to genomic instability and neoplastic transformation.

\section{Results}

Malignant D1T286A lymphocytes are aneuploid and exhibit chromosomal translocations

Because neoplastic cyclin D1 mutants accumulate in the nucleus during $S$ phase, we predicted that inappropriate activation of nuclear CDK4 during $S$ phase would perturb DNA replication fidelity, thereby inducing genomic instability. Indeed, lymphomas arising in Eu-D1T286A mice were uniformly aneuploid, exhibiting extensive chromosome gains and occasional chromosome loss (Fig. 1A; Supplementary Table S1). In addition, some E $\mu$ D1T286A tumors also exhibited nonclonal chromo-
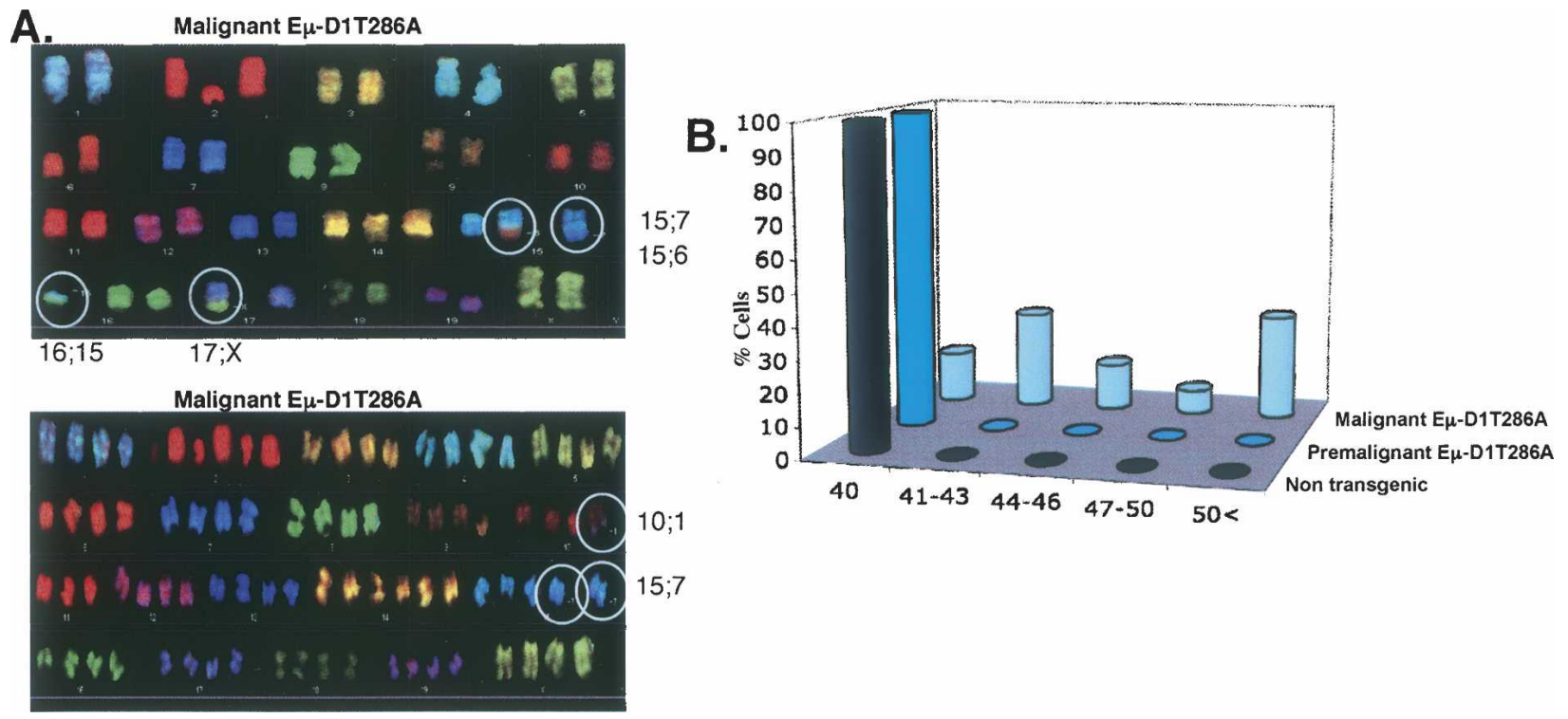

Figure 1. Malignant D1T286A lymphocytes are aneuploid. (A) Representative SKY analysis of tumors derived from D1T286A. (B) Quantification of the chromosome number per metaphase spread for nontransgenic (purple; 200/11; spreads per number of mice), premalignant D1T286A transgenic (blue; 100/9), and malignant D1T286A transgenic (light blue; 219/9) mice splenocytes. 
somal translocations (Fig. 1A). To determine if changes in ploidy occurred prior to or as a consequence of malignant conversion, we assessed the karyotype of premalignant and malignant splenic B cells expressing D1T286A. DAPI staining revealed aneuploidy in malignant D1T286A splenocytes; in contrast, premalignant D1T286A splenocytes and nontransgenic splenocytes retained a normal karyotype (Fig. 1B). The absence of aneuploidy in premalignant splenocytes may reflect the activation of a p53-mediated checkpoint that triggers the elimination of aneuploid cells. This hypothesis is investigated in detail below.

\section{Cdt1 is overexpressed in a D1T286A-dependent} manner

Aneuploidy could result from rereplication or loss of the spindle assembly checkpoint resulting in mitotic failure. To evaluate the spindle checkpoint, splenocytes from nontransgenic or transgenic mice were stimulated to enter the cell cycle and subsequently treated with noco- dazole to activate the spindle checkpoint. Both accumulated equivalent populations of phospho-H3-positive cells, consistent with checkpoint activation (Supplementary Fig. S1). We therefore considered DNA rereplication a strong possibility. Control of DNA replication is best understood with regard to regulated origin licensing. During G1 phase, DNA replication origins are established via loading of ORC (origin recognition complex) followed by Cdt1/CDC6-dependent loading of the replicative MCM helicase (Bell and Dutta 2002). Once origins are established, Cdt1 is degraded and CDC6 undergoes nuclear export to prevent reloading of origins during $S$ phase (Bell and Dutta 2002). The ability of overexpressed Cdt1 to promote DNA rereplication demonstrates that Cdt1 is rate-limiting (Vaziri et al. 2003). Immunoblot analysis of tumors that develop in Eu-D1T286A mice revealed overexpression of Cdt1 in 17 of 19 tumors (Fig. 2A), consistent with the idea that aneuploidy could reflect rereplication. Cdt1 overexpression was also apparent in premalignant splenocytes (Fig. 8B, below), suggesting that overexpression is an early event.
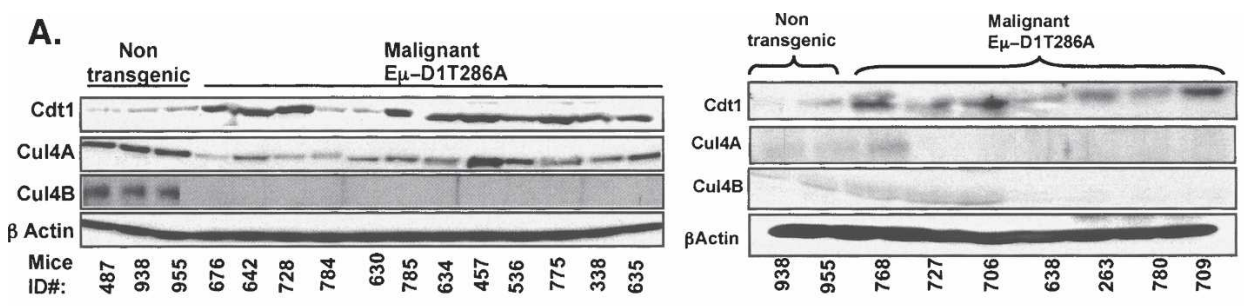

B.

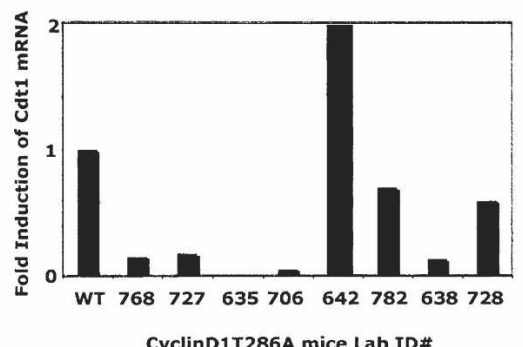

D.

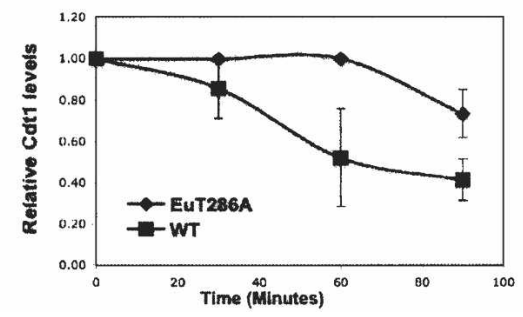

C.

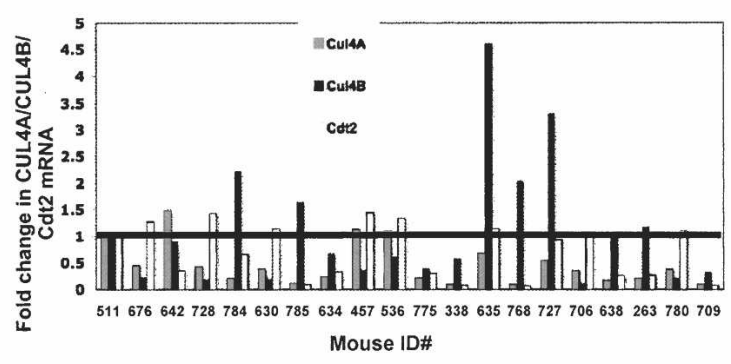

Figure 2. Cdt1 overexpression in D1T286A-expressing splenocytes. $(A) \mathrm{Cdt} 1$ and Cul4A/4B levels in tissues or tumors derived from nontransgenic or D1T286A mice were assessed by immunoblot analysis. $(B, C) \mathrm{Cdt1}$, Cul4A, Cul4B, and Cdt2 mRNA levels from nontransgenic spleen and D1T286A transgenic tumors were assessed by real-time RT-PCR using the Applied Biosystems 7900HT detection. $(D)$ The Cdt1 half-life in nontransgenic or transgenic splenocytes was determined following brief culture in RPMI-1640 complete media. Cells were treated with cycloheximide $(100 \mu \mathrm{g} / \mathrm{mL})$, harvested at the indicated intervals post-treatment, and subjected to Western analysis for Cdt1 and $\beta$ Actin. Cdt1 levels are expressed as an average of three independent experiments; bars represent standard error between experiments. 
RT-PCR analysis revealed decreased Cdt1 expression in most tumors (Fig. 2B), demonstrating that overexpression does not reflect increased Cdt1 transcription. We therefore considered deregulation of Cdt1 proteolysis. $\mathrm{Cdt} 1$ polyubiquitination and degradation are regulated through the activities of two distinct E3 ligases: SCFSkp2 and Cul4:DDB1 (Nishitani et al. 2006). To assess whether D1T286A triggered loss of components of either E3 ligase, we evaluated expression of Skp2, Cul4A, Cul4B, and Cdt2. Strikingly, Skp2 was overexpressed in Eu-D1T286A tumors (Supplementary Fig. S2). RT-PCR analysis revealed a complex relationship between D1T286A-Cdt1-Cul4A/B-Cdt2. In a majority of tumors, Cul4A and Cul4B message was reduced (Fig. 2C), concordant with increased levels of Cdt1 (2A). A smaller subset exhibited reduced Cdt 2 message, the specificity component that directs Cul4 to Cdt1 (Higa et al. 2006; Jin et al. 2006; Sansam et al. 2006), as well as Cul4 (e.g., tumors 634,775$)$. These results reveal that a majority of tumors exhibit reduced levels of the Cul4-Cdt2 ligase, with a concordant increase in Cdt1 expression. Based on this observation, we predicted reduced Cdt1 degradation in D1T286A transgenic lymphocytes. Indeed, in nontransgenic splenocytes, the Cdt1 half-life was $\sim 40$ min whereas in D1T286A splenocytes it was $>90 \mathrm{~min}$ (Fig. 2D).

To further evaluate the relationship between nuclear retention of cyclin D1/CDK4 and Cdt1 accumulation, we determined whether acute expression of nuclear cy- clin D1T286A could inhibit Cdt1 proteolysis. HeLa cells were utilized due to their high efficiency of transfection. Proliferating cells were transfected with plasmids encoding myc-tagged Cdt1, GFP, CDK4, and either wild-type cyclin D1 or D1T286A. Cdt1 levels were assessed in G1 phase (Cdt1 stable) or S phase (Cdt1 unstable). Cdt1 levels were dramatically reduced in S phase (Fig. 3A, lanes 1,2). Expression of D1T286A inhibited S-phase-specific Cdt1 loss (Fig. 3A, lanes 3,4). In contrast, expression of wild-type cyclin D1 did not attenuate Cdt1 degradation (Supplementary Fig. S3). Additionally, coexpression of kinase-dead CDK4K35M with D1T286A did not stabilize Cdt1 (Supplementary Fig. S3), revealing kinase dependence. The inability of CDK4K35M to attenuate Cdt1 loss does not reflect cell cycle effects, as CDK4K35M does not elicit cell cycle arrest (van den Heuvel and Harlow 1993). Consistent with D1T286A triggering loss of Cul4A/B in vivo, acute expression of D1T286A in cell culture triggered Cul4A (Fig. 3A,B) and Cul4B (Fig. 3B) loss during S phase.

If decreased Cdt1 turnover reflects loss of Cul4A and $\mathrm{B}$, re-expression of either Cul4 protein should restore Sphase loss of Cdt1 (Nishitani et al. 2006). Indeed, expression of myc-tagged Cul4A (Fig. 3C) or Cul4B (Fig. 3D) restored Cdt1 loss during $S$ phase even when D1T286A was expressed (Fig. 3D). In contrast, expression of neither Skp2 (Fig. 3C) nor Cdt2/DDB1 (Fig. 3D) could inhibit D1T286A-dependent stabilization of Cdt1. D1T286A also inhibited DNA damage-dependent Cdt1 loss
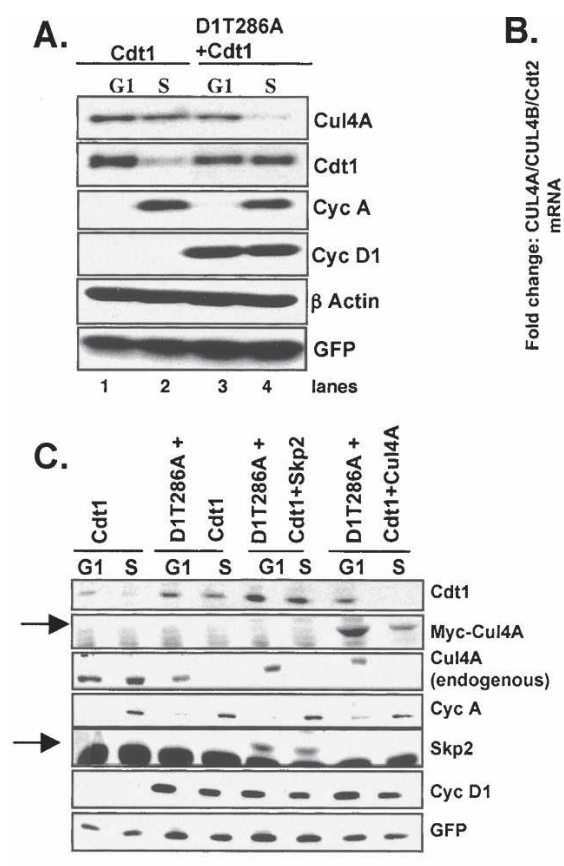

E.

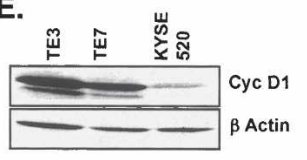

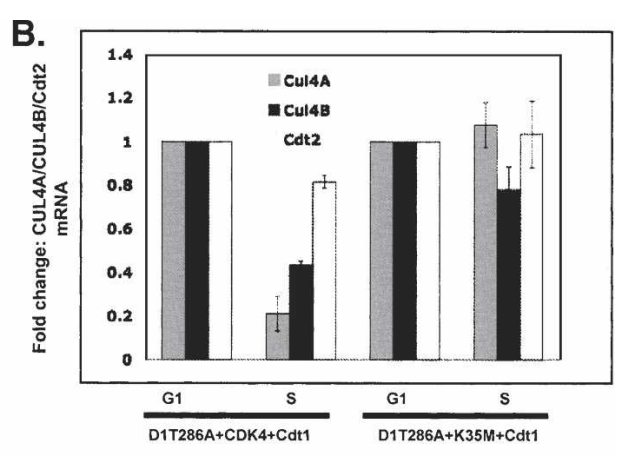

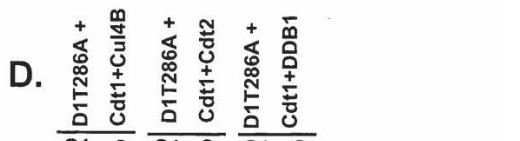

F.

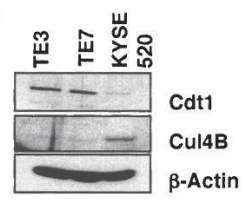

Figure 3. Acute inhibition of Cdt1 proteolysis by the cyclin D1T286A/CDK4 kinase. $(A)$ HeLa cells transfected with the indicated plasmids along with myc-Cdt1 were treated with nocodazole for 16-18 h, after which cells were shaken off and replated in two plates: The first plate, in complete media, was harvested $8 \mathrm{~h}$ after release (G1 phase); in the second dish, HU was added and cells were harvested $14 \mathrm{~h}$ after shake-off (S phase). Levels of Cdt1, cyclin A (marker for S phase), cyclin $\mathrm{D} 1, \beta$-Actin, and GFP were determined by immunoblot. $(B)$ Cul4A/4B and Cdt2 mRNA levels determined by real-time RT-PCR from HeLa cells synchronized in either G1 or S phase (as in $A$ ) following transfection with vectors encoding D1T286A along with either wild-type or kinase-dead CDK4. Target mRNAs were normalized to actin and expressed as fold change between G1 and S phase. $(C, D)$ HeLa cells were transfected with the indicated plasmids and synchronized in G1 or S phase. Lysates prepared from these cells were analyzed by immunoblot with antibodies directed toward the proteins indicated to the right. $(E, F)$ Western analysis of soluble lysates prepared from TE3, TE7 (which express endogenous cyclin D1P287A), and KYSE-520 human esophageal cancer cell lines for cyclin D1, Cul4B, $\beta$ Actin, and Cdt1. 
(Supplementary Fig. S4). These data demonstrate that the D1T286A/CDK4 kinase is inhibiting Cul4-dependent Cdt1 proteolysis.

We next assessed the relevance of this observation in human cancer. We previously identified human esophageal carcinoma-derived cell lines harboring a mutant cyclin D1 allele, D1P287A (Benzeno et al. 2006). Cyclin D1P287A is refractory to GSK3 $\beta$-dependent phosphorylation and is thus stabilized in the nucleus. As observed previously, cyclin D1 accumulation is enhanced (Fig. 3E) in TE3/7 cell lines (D1P287A allele) relative to KYSE520 (wild-type cyclin D1) due to inhibition of Thr286 phosphorylation (Benzeno et al. 2006). Based on our analysis of the Eu-D1T286A tumors, we predicted that D1P287A accumulation should be accompanied by Cdt1 overexpression and decreased Cul4 expression. Indeed, Cdt1 was overexpressed in both TE3 and TE7 cells (Fig. 3F). Conversely, we observed decreased levels of Cul4B (Fig. $3 \mathrm{~F}$ ) and Cdt 2 mRNA (data not shown) in cells harboring D1P287A. While no decrease in Cul4A was observed (data not shown), the loss of both Cul4B and Cdt2, which is necessary for targeting of $\mathrm{Cdt} 1$, is expected to attenuate Cdt1 proteolysis.

The D1T286A/CDK4 kinase induces MCM chromatin retention during $S$ phase, resulting in DNA rereplication

D1T286A-dependent Cdt1 overexpression could trigger the reloading of the MCM helicase during $S$ phase and hence DNA rereplication. Initially, we addressed this in p53 wild-type NIH3T3 cells. Cells programmed to overexpress either wild-type cyclin D1 or D1T286A were synchronized at the G1/S boundary with hydroxyurea (HU) released in medium lacking $\mathrm{HU}$, and chromatinbound proteins were collected (Gladden and Diehl 2003). Western analysis of chromatin-associated fractions revealed that MCM3 and MCM7 were displaced from chromatin as a consequence of S-phase progression in D1-3T3 cells, but in D1T286A-3T3 a significant fraction of MCM3/7 was retained on chromatin throughout $S$ phase (Fig. 4A). Both D1T286A-3T3 and D1-3T3 cells exhibited similar kinetics of S-phase progression, demonstrating that increased loading of MCM complexes did not reflect disproportionate S-phase intervals (Supplementary Table S2). We also evaluated S-phase loading of MCM3/MCM7 in TE3/7 esophageal carcinoma cell lines. Consistent with decreased Cdt1 turnover, MCM3 and MCM7 were retained during late $S$ phase in both TE3 and TE7 cell lines, whereas both dissociated from chromatin during late S phase in KYSE520 (Fig. 4B). Kinetics of S-phase progression among the distinct esophageal cell lines were comparable (Supplementary Table S3).

To ensure that S-phase loading of MCM does not reflect cell line establishment, we determined the capacity of acutely introduced D1T286A to promote MCM chromatin loading during $S$ phase. Cells transfected with Cdt1 alone or Cdt1 along with either D1T286A and wildtype CDK4 or kinase-dead CDK4K35M and synchro-

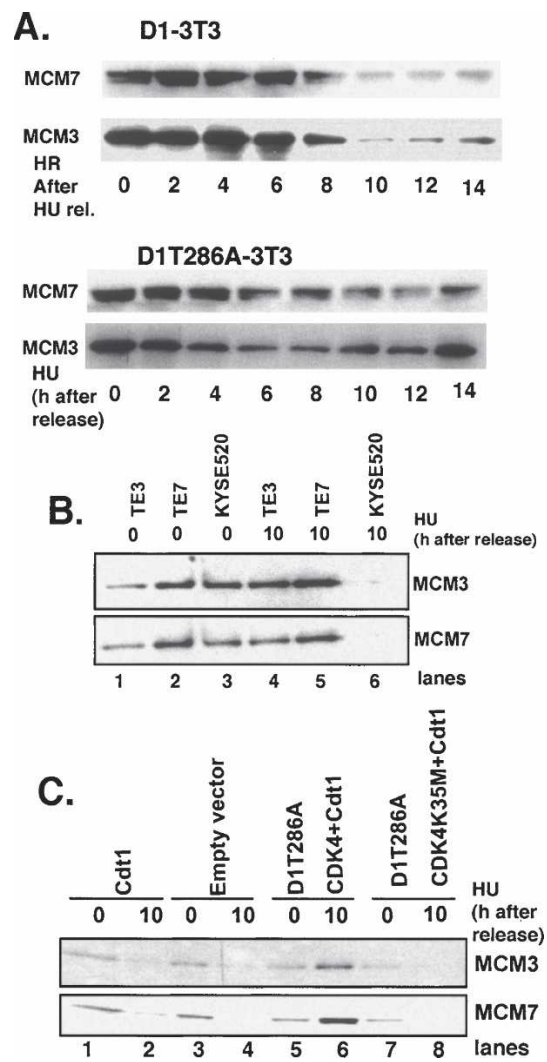

Figure 4. Cyclin D1-dependent stabilization of Cdt1 promotes reloading of MCM during $\mathrm{S}$ phase. (A) NIH-3T3 cell lines overexpressing cyclin D1 or D1T286A were synchronized with HU for $24 \mathrm{~h}$ and released in complete medium lacking HU. Chromatin-bound proteins were analyzed by Western analysis for MCM3 and MCM7 at the indicated intervals following replating in media without HU. (B) TE3, TE7, and KYSE-520 cell lines were synchronized at the G1/S boundary with HU for $24 \mathrm{~h}$. Chromatin-bound proteins were assessed at 0 and $10 \mathrm{~h}$ post-HU release. $(C)$ HeLa cells transfected with the indicated plasmids synchronized at the G1/S boundary with HU for $24 \mathrm{~h}$. Chromatin-bound proteins were assessed at 0 and $10 \mathrm{~h}$ post-HU.

nized with HU were released in complete media, and chromatin-bound proteins were collected immediately following release or at $10 \mathrm{~h}$ post-release (late $\mathrm{S}$ phase as determined by FACS). MCM complexes were displaced from chromatin by late $S$ phase in cells transfected with an empty vector or Cdt1 alone (Fig. 4C, lanes 1-4). In contrast, in cells expressing Cdt1 along with D1T286A and wild-type CDK4, chromatin-bound MCM3/7 increased during $S$ phase rather than being displaced (Fig. 4C, lanes 5,6). This phenotype was dependent on CDK4 activity, as expression of CDK4K35M failed to prevent MCM loss from chromatin (Fig. 4C, lanes 7,8).

Reloading of MCM during $S$ phase is expected to promote refiring of origins of replication and induce rereplication. We therefore determined whether the D1T286A/CDK4 kinase would cooperate with Cdt1 to induce the accumulation of cells harboring $>4 \mathrm{~N}$ DNA content as a marker of DNA rereplication in $\mathrm{H} 1299$ cells; this cell line was previously used to assess the ability of 
Cdt1 to drive DNA rereplication (Vaziri et al. 2003). Overexpression of Cdt1 alone did not induce significant rereplication (Fig. 5A), reflecting the capacity of cells to degrade Cdt1 in the absence of D1T286A during S phase (Fig. 3A). Expression of D1T286A along with CDK4, which is limiting following acute expression of cyclin
A.
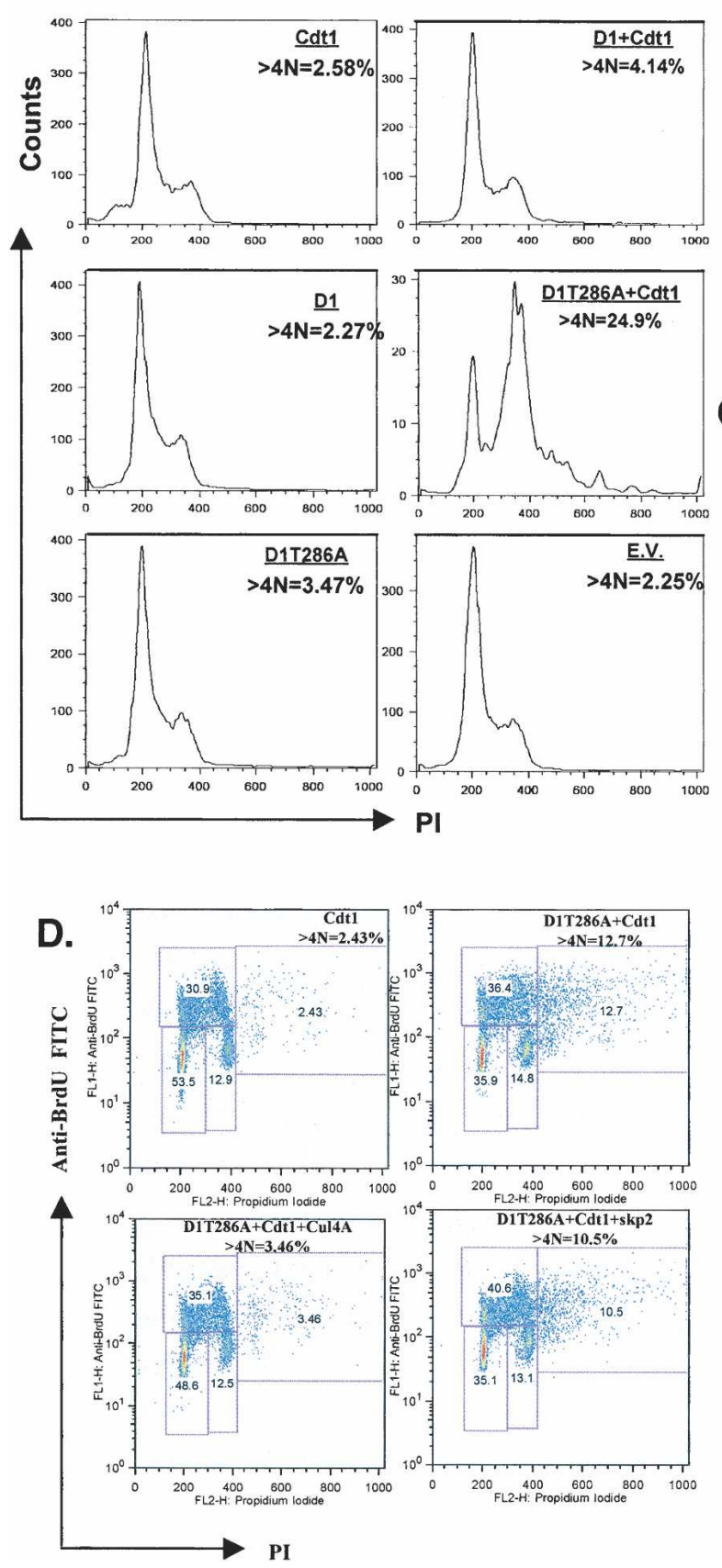

B.
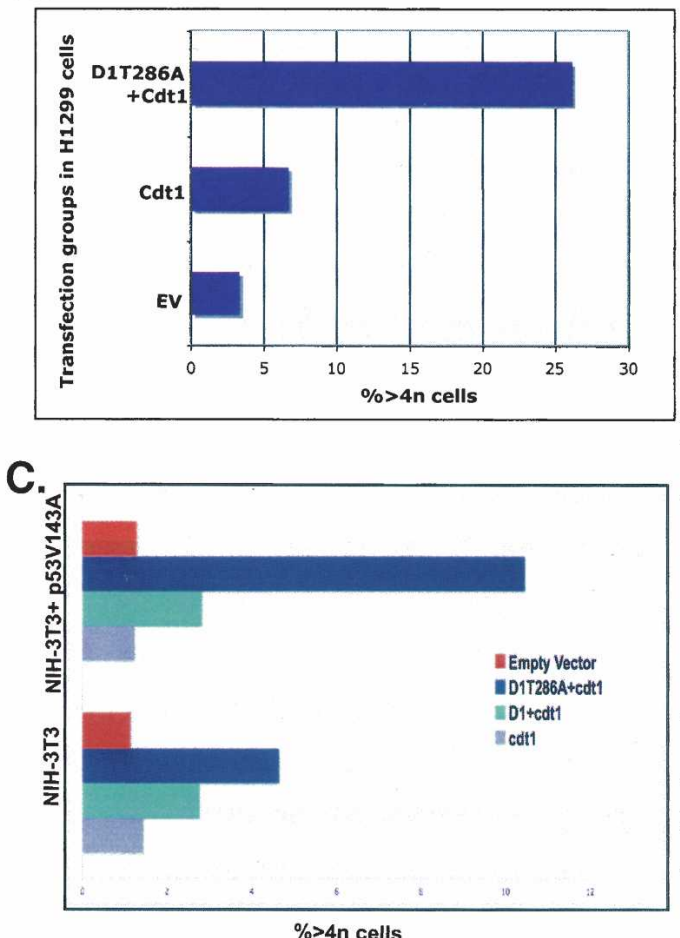

Figure 5. Cdt1 cooperates with the D1T286A-dependent kinase to induce p53-dependent DNA rereplication. $(A)$ H1299 cells transfected with indicated cyclin expression vectors, and CDK4 along with GFP and Cdt1 where indicated, were stained with propidium iodide and analyzed by flow cytometry following gating on the GFP-positive cell population. (B) H1299 cells were transfected with plasmids encoding Cdt1, Cdt1 along with D1T286A and CDK4, or empty vector and treated with nocodazole (G2-M block) 10 h after transfection. Fifteen hours following nocodazole, cells were harvested by mitotic shake-off, and cell cycle profile was assessed by propidium iodide staining. The percentage of cells in a representative experiment showing $>4 \mathrm{~N}$ DNA content is represented graphically. (C) NIH-3T3 cells were transfected with the indicated expression plasmids with or without p53V143A and analyzed as in $A$. Graphic quantification of the percentage of $>4 \mathrm{~N}$ cells (rereplication). (D) Reintroduction of Cul4A, but not Skp2, inhibits D1T286Adependent rereplication. 
D1, induced marginal but reproducible accumulation of $>4 \mathrm{~N}$ cells (Fig. 5A) within the time frame of this experiment, suggesting that endogenous Cdt1 may not accumulate sufficiently within the context of a single cell cycle to promote efficient DNA rereplication. Consistent with this hypothesis, coexpression of Cdt1 along with D1T286A resulted in a significant increase in the $>4 \mathrm{~N}$ population (Fig. 5A). In contrast, wild-type cyclin D1 did not cooperate with Cdt1 to promote rereplication, consistent with its inability to stabilize Cdt1. Critically, the $>4 \mathrm{~N}$ population of cells induced by D1T286ACdt1 incorporated BrdU into their DNA, demonstrating that these cells were replicating their DNA and had not arisen due to mitotic failure (Fig. 5D). In addition, the accumulation of the $>4 \mathrm{~N}$ cell population was not inhibited by nocodazole treatment, verifying rereplication within a single $S$ phase (Fig. 5B).

H1299 cells are deficient in p53, and the capacity of Cdt1 to drive DNA rereplication in these cells reflects loss of p53 (Vaziri et al. 2003). To assess p53 function in D1T286A/Cdt1-dependent rereplication, we utilized NIH3T3 cells that harbor wild-type p53. While very little rereplication could be detected in NIH3T3 cells, coexpression of dominant-negative p53V143A /Opitz et al. 2001) permitted a significant accumulation of cells with $>4 \mathrm{~N}$ DNA content (Fig. 5C), consistent with the notion that accumulation of rereplicating cells requires inactivation of $\mathrm{p} 53$. We also assessed rereplication in human esophageal-derived cancer cells harboring endogenous cyclin D1P287A. KYSE520, TE3, or TE7 cells were synchronized at the G1/S boundary with $\mathrm{HU}$ and released in media containing nocodazole and BrdU for 15 $h$, and accumulation of cells with $>4 N$ DNA content was measured. Both TE3/7 cell lines exhibited $>16 \%$ of cells with $>4$ N DNA content, all of which incorporated BrdU (Supplementary Fig. S5). In contrast, KYSE520 exhibited $\sim 7 \%$ of cells with $>4 \mathrm{~N}$. The ability of D1T286A to regulate S-phase accumulation of Cdt1 suggests that this reflects an Rb-independent function of the D1T286A/ CDK4 kinase. Consistent with this idea, expression of D1T286A in HeLa cells, where Rb is inactivated due to expression of the HPV E7 tumor antigen, drove rereplication (Supplementary Fig. S6). Finally, we addressed whether reintroduction of Cul4, which restores Cdt1 turnover during S phase, could inhibit D1T286A-dependent rereplication. Significantly expression of Cul4A but not Skp2 blocked D1T286A-dependent rereplication (Fig. 5D). Collectively, these data demonstrate a direct relationship between nuclear accumulation of active cyclin D1/CDK4 during S phase, loss of Cul4, and induction of DNA rereplication.

\section{Expression of D1T286A in splenic lymphocytes} induces a DNA damage response

Because DNA rereplication is associated with induction of DSBs and p53 activation, we assessed p53 activation and the underlying mechanism in E $\mu$-D1T286A transgenic mice. p53 activation in premalignant splenic tissue from E $\mathrm{L}-\mathrm{D} 1 \mathrm{~T} 286 \mathrm{~A}$ mice was determined by immunohis- tochemistry (IHC) using a p-S15 antibody. Transgenic spleens exhibited prominent phospho-p53 staining, while no staining was evident in nontransgenic mice (Fig. 6A; Supplementary Table S4). p53 is activated by numerous pathways, including inappropriate expression of oncogenes and DNA damage (Sherr 1998). Because E $\mu-$ D1T286A localizes to the nucleus during S phase, we considered the potential of nuclear cyclin D1 to trigger DNA damage. Mediators of the DNA damage checkpoint pathway include ATM, which senses DSBs and subsequently triggers phosphorylation of CHK2, p53, and $\gamma \mathrm{H} 2 \mathrm{AX}$ (Kastan and Bartek 2004). If D1T286A-dependent p53 activation is a critical step in neoplastic conversion, it should be apparent in preneoplastic cells. Consistent with this notion, premalignant tissue exhibited robust induction of p-ATM, p-CHK2, and $\gamma \mathrm{H} 2 \mathrm{AX}$ (Fig. 6B; Supplementary Table S4). Malignant tissue also exhibited positive, but reduced, staining for checkpoint components, suggesting the DNA damage checkpoint might be compromised as a consequence of malignant conversion. We confirmed the accumulation of $\gamma \mathrm{H} 2 \mathrm{AX}$ by Western blot analysis of histone extracts (Fig. 6C). Nontransgenic tissue exhibited undetectable $\gamma \mathrm{H} 2 \mathrm{AX}$ accumulation (Supplementary Fig. S7). The activation of the DNA damage checkpoint did not reflect long-term exposure to the D1T286A transgene because transient overexpression of constitutively nuclear cyclin D1 alleles in cultured cells triggered $\gamma \mathrm{H} 2 \mathrm{AX}$ accumulation (Fig. 6D) and accumulation of p-ATM and p-CHK2 (Fig. 6E), suggesting that nuclear D1 leads to increased induction of DSBs or alterations in chromatin structure. To further assess physiological relevance, we performed IHC for cyclin D1b and $\gamma \mathrm{H} 2 \mathrm{AX}$ on primary esophageal carcinomas (Fig. 6F), a cancer that frequently expresses cyclin D1b (Lu et al. 2003). Thirteen of 19 tumors strongly expressed cyclin $\mathrm{D} 1 \mathrm{~b}$; of these, nine were positive for $\gamma \mathrm{H} 2 \mathrm{AX}$, consistent with induction of a DSB response in human cancer by this oncogenic isoform of cyclin D1.

\section{Targeted deletion of p53 accelerates D1T286A-dependent lymphoma development, genomic instability, and reduced apoptosis}

Cyclin D1T286A lymphoma onset occurs at 13 mo and correlates with p53 inactivation, increased proliferation, and decreased apoptosis, suggesting that cell death and tumor latency are p53 dependent (Gladden et al. 2006). To address the role of p53 in suppression of Eu-D1T286A tumorgenicity and apoptosis, transgenic mice were intercrossed with $\mathrm{p} 53^{+/-}$mice to generate cohorts of E $\mu$ D1T286A transgenic mice on both a $\mathrm{p} 53^{+/-}$and $\mathrm{p} 53^{-/-}$ background. The Eu-D1T286A/p53 ${ }^{+/-}$mice exhibited a latency of only 6 mo (Fig. 7A). Deletion of one p53 allele did not alter the tumor spectrum, as E $\mu-D 1 T 286 \mathrm{~A} / \mathrm{p} 53^{+/-}$ mice developed a high-grade diffuse B-cell lymphoma (Fig. 7B) that is phenotypically and molecularly similar

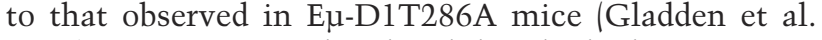
2006). Tumors were clonal, exhibited a high mitotic index, retained cyclin D1T286A, and were positive for the B-cell markers B220 and CD19 and negative for CD3 (Fig. 

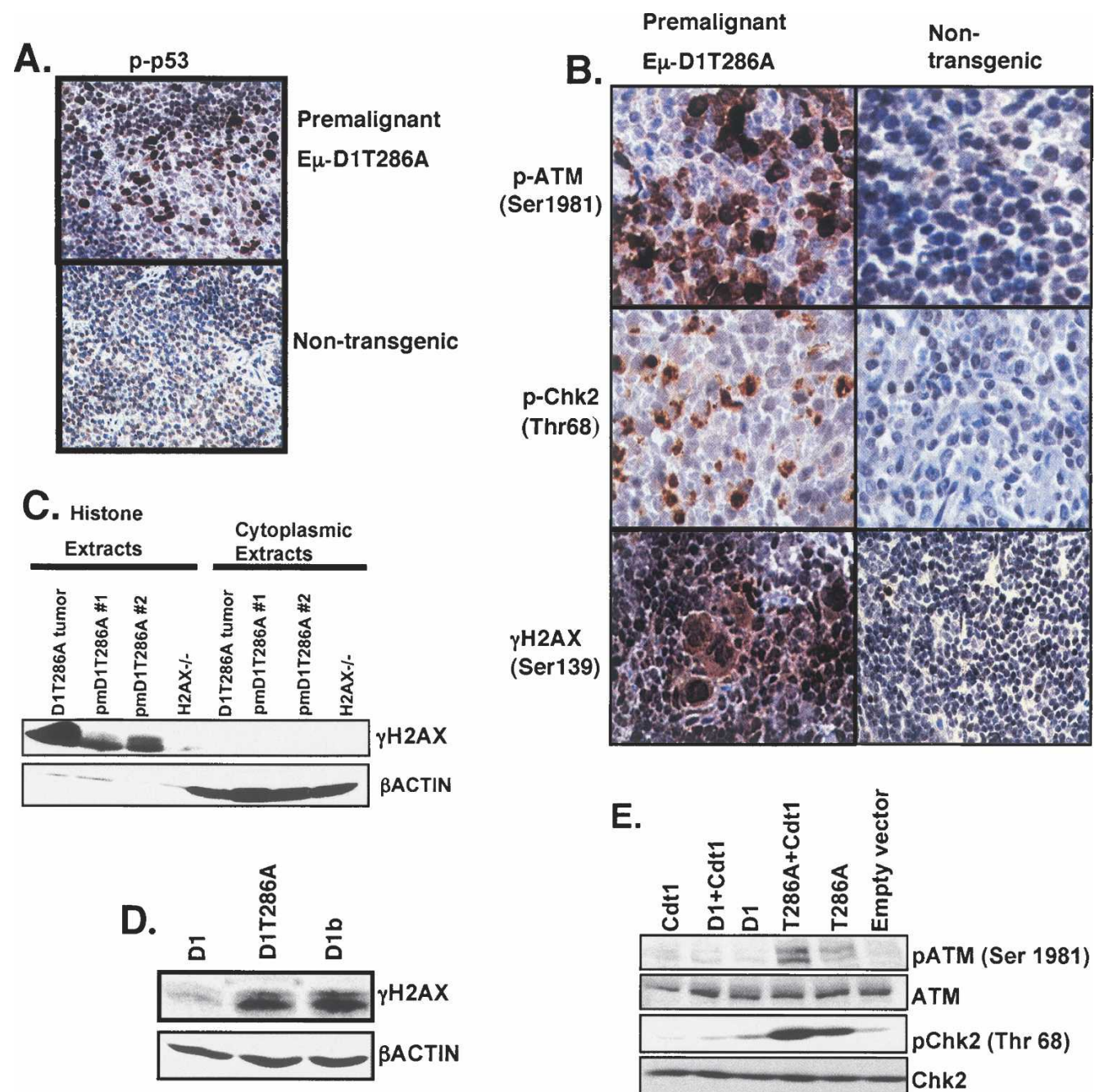

\section{E.}

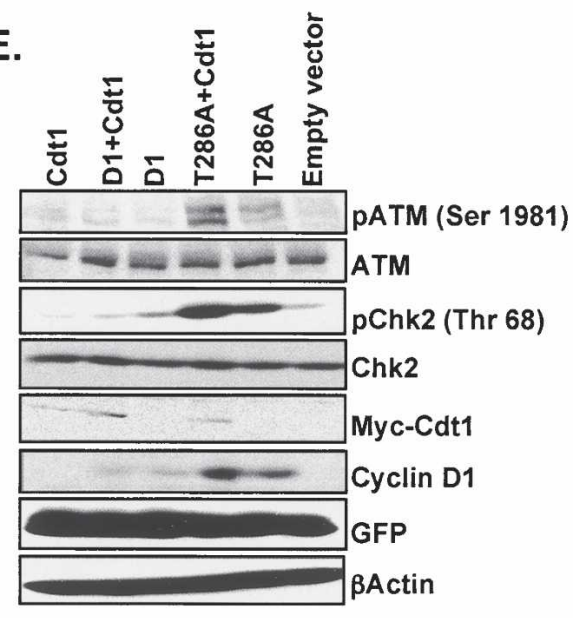

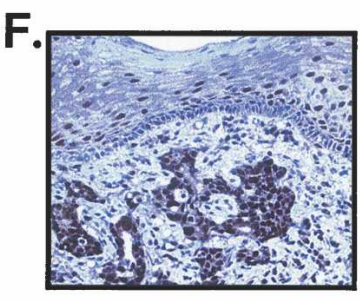

Cyclin D1b

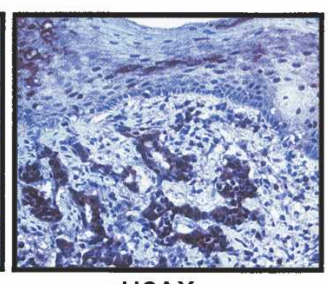

$\gamma \mathrm{H} 2 \mathrm{AX}$

Figure 6. Expression of D1T286A in splenic lymphocytes induces a DNA damage response. (A) IHC of premalignant D1T286A transgenic (top) and age-matched nontransgenic (bottom) spleens for p-p53 (S-15). (B) IHC of p-ATM (S1981) (top panel), p-Chk2 (T68) (middle panel), and $\gamma$-H2AX (S139) (bottom panel) in premalignant D1T286A transgenic (left panel) and age-matched nontransgenic (right panel) mice. (C) Accumulation of $\gamma \mathrm{H} 2 \mathrm{AX}$ in histone extracts prepared from D1T286A transgenic tumor. $\beta$-Actin was used as a loading control for cytoplasmic extract lysates. $(D)$ Lysates prepared from U2OS cells, transfected as indicated, were subjected to immunoblot for $\gamma \mathrm{H} 2 \mathrm{AX}$ and $\beta$ Actin. $(E)$ Lysates prepared from HeLa cells transfected with the indicated plasmids were subjected to immunoblot for p-ATM, total ATM, p-Chk2, total Chk2, GFP (transfection control), and $\beta$-Actin. (F) Representative IHC for cyclin $\mathrm{D} 1 \mathrm{~b}$ and $\gamma \mathrm{H} 2 \mathrm{AX}$ from esophageal adenocarcinoma.

7C,D; Supplementary Fig. S8). Lymphomas also exhibited accumulation of $\operatorname{IgM}^{+} / \mathrm{IgD}^{-}$B lymphocytes; in contrast, no such enrichment was observed in $\mathrm{p} 53^{+/-}$mice

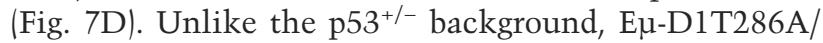
p53 ${ }^{-/-}$mice routinely developed T-cell lymphoma at
3 mo of age and were not used for further analysis. At the molecular level, tumors arising in E $\mu-D 1 T 286 \mathrm{~A} / \mathrm{p}^{2} 3^{+/-}$ uniformly overexpressed Cdt1 (Fig. 8A) and were aneuploid (Fig. 8C). Consistent with Cdt1 overexpression functioning as an initiating event, overexpression was 
A.

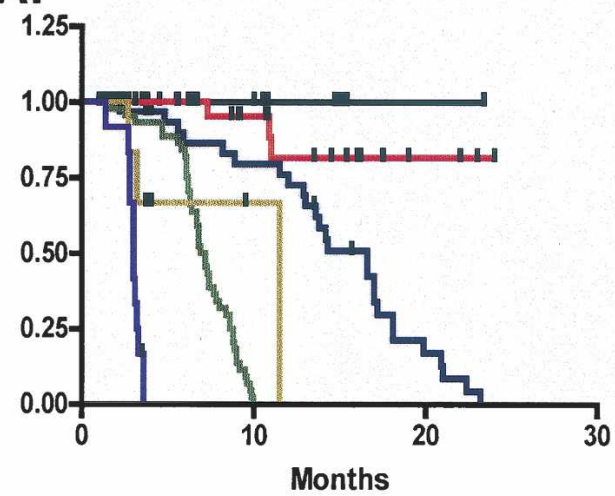

B.

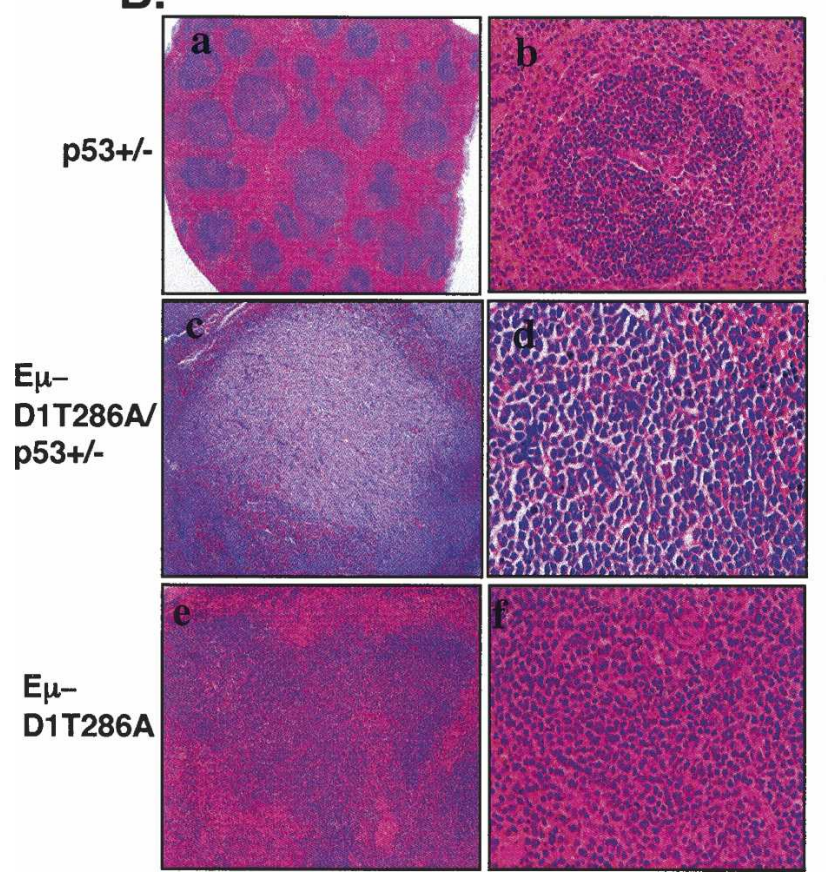

C.
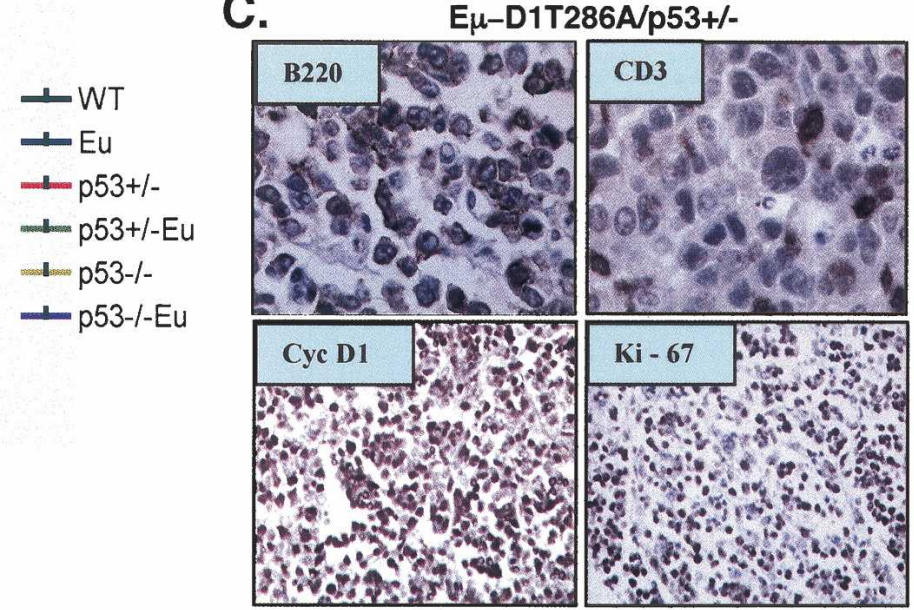

D.

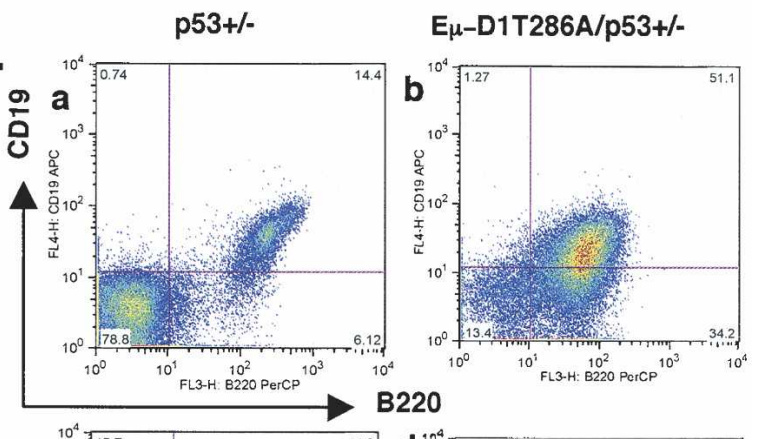

Figure 7. Targeted deletion of p53 accelerates B-cell lymphoma development. (A) Survival curves representing nontransgenic (black line; $n-25), \mathrm{D} 1 \mathrm{T286A}$ (blue line; $n=36), \mathrm{p} 53^{+/-}\left(\right.$red line; 28), D1T286A $/ \mathrm{p} 53^{+/-}$(green line; $\left.n=44\right), \mathrm{p} 53^{-/-}$(yellow line; $\left.n=5\right)$, and D1T286A/p53-/- (purple line; $n=12$ ) cohorts over a $24-$ mo period. $(B)$ Representative histology of p53 ${ }^{+/-}$spleen at the magnification of $4 \times\left(\right.$ panel $a$ ) and $40 \times\left(\right.$ panel $b$ ), a tumor-burdened p53 ${ }^{+/-}$D1T286A spleen at $4 \times($ panel $c$ ) and $40 \times($ panel $d)$, or a D1T286A tumorburdened spleen at $4 \times($ panel $e$ ) and $40 \times$ (panel $f$ ) stained with hematoxylin and eosin. $(C)$ Immunohistochemical staining of D1T286A/ p53 $3^{+/}$spleens for B220, cyclin D1, CD3, and Ki-67. (D) Splenocytes from a cohort of age-matched p53 ${ }^{+/-}(a, c)$ or D1T286A/p53 ${ }^{+/-}$ tumor-burdened (panels $b, d$ ) mice were analyzed by flow cytometry with antibodies specific for B220 and CD19 (panels $a, b)$ or surface $\operatorname{IgM}$ and $\operatorname{IgD}($ panels $c, d)$.

apparent in premalignant cells (Fig. 8A,B). In contrast to

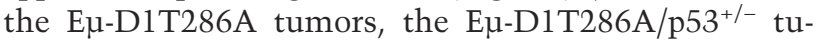
mors exhibited clonal translocations (Fig. 8C; Supplementary Table S5). Tumors arising in the $\mathrm{p} 53^{+/-}$background exhibited loss of heterozygosity (LOH) (data not shown), consistent with p53 playing a significant role in suppressing neoplastic growth.

The absence of aneuploidy in premalignant $\mathrm{E} \mu$ D1T286A cells (Fig. 1B) implied that DNA damage induced by D1T286A-dependent rereplication triggers p53- dependent apoptosis. If so, loss of a single p53 allele should reduce apoptosis in premalignant splenocytes. Indeed, deletion of a single p53 allele was sufficient to abrogate the D1T286A-dependent increase in apoptosis $(P<0.05)$ (Fig. 8D, column 3). The absence of p53-dependent apoptosis resulted in a significant increase in cell aneuploidy in premalignant D1T286A/p53 ${ }^{+-}$splenocytes as determined by examination of metaphase spreads (Fig. 8E) or FACS analysis (Fig. 8F). Aneuploidy did not solely reflect loss of p53, as deletion of p53 in the 
A.

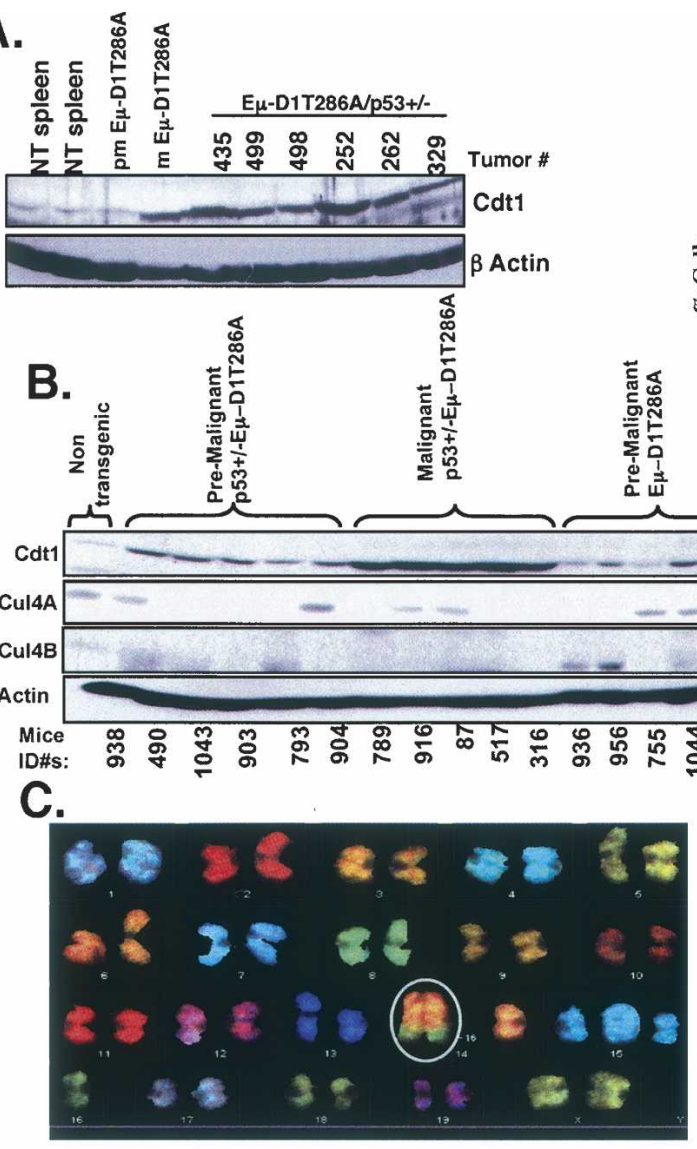

D.

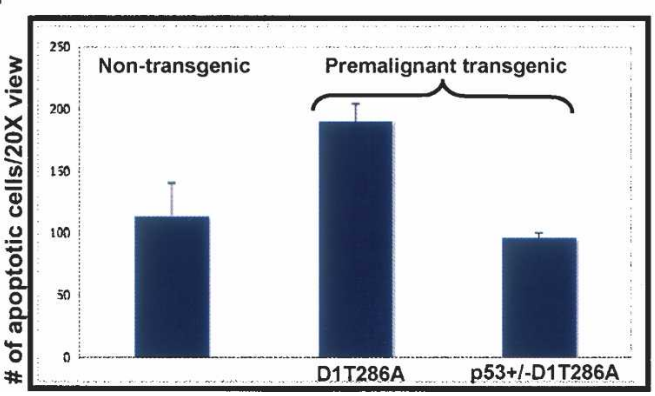

E.

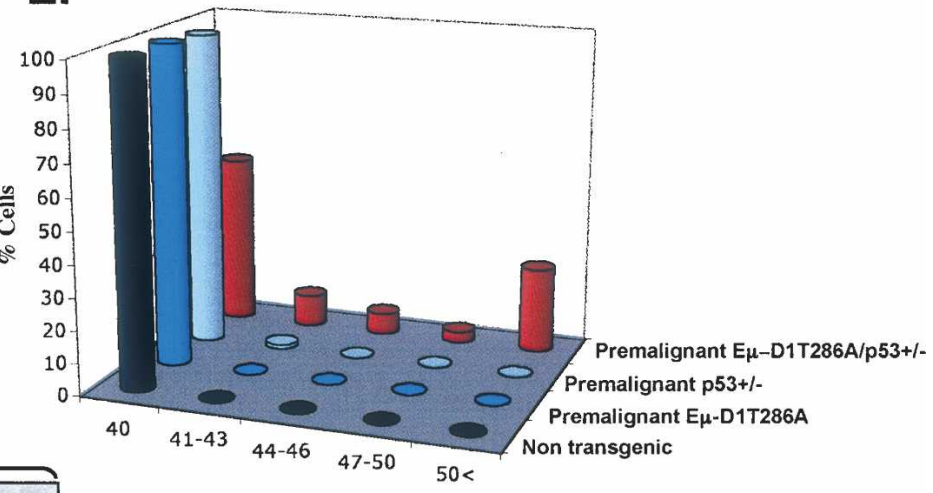

F.
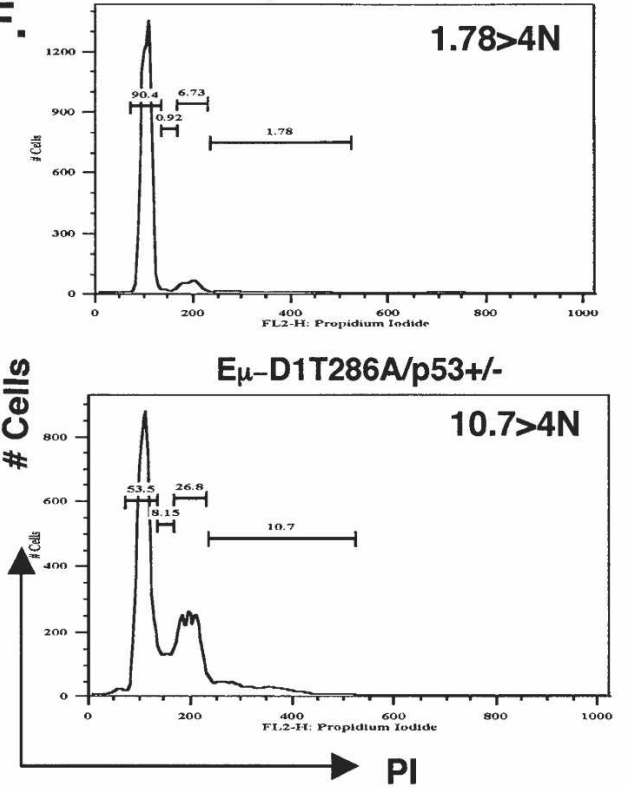

Figure 8. Deletion of p53 decreases D1T286A-dependent apoptosis and accelerates the accumulation of aneuploid cells. $(A)$ Cdt1 levels in tumors derived from D1T286A/p53 ${ }^{+-}$mice. (B) Cdt1 levels in nontransgenic spleens or from premalignant versus malignant

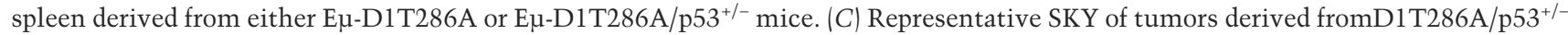
mice. $(D)$ Quantification of TUNEL-positive cells in premalignant D1T286A, D1T286A/p53+/-, or age-matched nontransgenic control. $(E)$ Quantification of the chromosome number per metaphase spread for nontransgenic (purple), premalignant D1T286A transgenic (blue), premalignant $5^{+/-}$(light blue), and premalignant D1T286A/p53 $3^{+-}$(red) mice. One-hundred to 200 metaphase spreads from

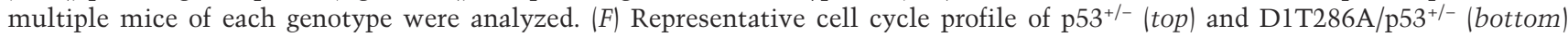
splenocytes.

absence of D1T286A expression did not promote the accumulation of aneuploid cells (Fig. 8F).

\section{Discussion}

$D N A$ rereplication, the DNA damage checkpoint, and tumorigenesis

Previous work revealed that an oncogenic mutant allele of cyclin D1 that is refractory to nuclear export and ubiq- uitin-mediated proteolysis, D1T286A, can accelerate MCM chromatin loading during G1 phase (Gladden and Diehl 2003). This observation in concert with D1T286A localization to the nucleus during $S$ phase suggested that the D1T286A kinase might disrupt "the once and only once" regulation of DNA replication by maintaining or reloading the MCM helicase during $S$ phase. Indeed, the D1T286A/CDK4 kinase inhibits Cdt1 proteolysis, leading to Cdt1 overexpression in vitro and in vivo. The cy- 
clin D1T286A/CDK4 kinase triggers Cdt1 stabilization in cell culture, in D1T286A transgenic mice, and in human tumor-derived cell lines that harbor a constitutively nuclear and stable cyclin D1 mutant. Overexpression of Cdt1 correlates with chromosomal gains, resulting in cellular aneuploidy, genomic instability, and neoplastic growth. Mechanistically, Cdt1 overexpression promoted maintenance of the MCM helicase during $S$ phase, triggering DNA rereplication.

The deleterious effects of D1T286A-dependent DNA rereplication and genomic instability is initially opposed by p53-dependent apoptosis that occurs in response to DNA breaks, perturbations in DNA replication, and oncogene activation (Kastan and Bartek 2004). While it is clear that p53 function is essential for tumor suppression, the precise signals that mediate p53 activation during tumorigenesis are not precisely defined. This work supports a model wherein DNA rereplication triggers DNA damage checkpoint activation of p53.

Cells expressing D1T286A and accumulating Cdt1 activate the ATM-CHK2-p53 DNA damage checkpoint, consistent with this checkpoint playing a tumor-suppressive role. Recent work has correlated oncogene-induced senescence with induction of the DNA damage checkpoint in solid tumors (Bartkova et al. 2006; Di Micco et al. 2006). Our work is consistent with DNA damage signaling as a critical tumor-suppressive pathway. Premaliganant tissue exhibited a marked increase in phospho-ATM, p-CHK2, and p-p53. Malignant conversion correlated with loss of p53, suggesting a strong selection for inactivation of this pathway. Of note, we observed no induction of senescence-associated markers in premalignant or malignant tissue, suggesting that senescence does not play a prominent tumor-suppressive role (negative data not shown). Rather, rereplication and DNA damage correlate with p53-dependent apoptosis. Consistent with this model, targeted deletion of p53 reduced apoptosis and accelerated tumor onset.

In the ATM-CHK2-p53 pathway, ATM senses DSBs, whereupon it triggers the activation of downstream targets $\mathrm{CHK} 2$ and p53. How does rereplication trigger DSBs? Recent work has revealed that small DNA fragments are generated as a consequence of replication fork collision during rereplication (Davidson et al. 2006). The generation of such fragments would provide the activating DSB signal for the ATM pathway. The increased frequency of DNA damage (e.g., DSBs) in turn would be expected to contribute a higher frequency of DNA repair errors, thereby leading to an increase in chromosomal translocations as are observed in D1T286A tumors.

Analysis of D1T286A and D1T286A/p53+/- tumors revealed overexpression of $\mathrm{Cdt} 1$ due to attenuated protein degradation, suggesting that nuclear accumulation of D1T286A during S phase opposes Cdt1 proteolysis. Accumulation of Cdt1 can be regulated by both the $\mathrm{SCF}^{\mathrm{SKP} 2}$ - and Cul4-based E3 ubiquitin ligases (Nishitani et al. 2006). Tumors arising in D1T286A mice downregulate $\mathrm{Cul} 4 \mathrm{~A}$ and $\mathrm{Cul} 4 \mathrm{~B}$ but retain or overexpress Skp2, suggesting that inhibition of Cdt1 proteolysis re- sults from a loss of the Cul4 ligase. Indeed, restoration of either Cul4A or Cul4B restored Cdt1 proteolysis.

Loss of Cul4 mRNA suggests that the D1T286A/ CDK4 kinase directly or indirectly represses Cul4 expression. Numerous studies have provided links between cyclin D1 and transcriptional regulators and histone-modifying enzymes (Ewen and Lamb 2004). With regard to transcription regulation, cyclin D1 action is either repressive or activating, likely depending on promoter context. It is tempting to speculate that the D1T286A/CDK4 kinase targets transcriptional complexes that play requisite roles in transcriptional activation of the Cul4 promoters. Because there is no published work regarding regulation of Cul4 expression, it is difficult to predict how cyclin D1T286A could contribute to its regulated expression. Current efforts are focused on determining whether Cul4A is a direct target.

While loss of Cul4A and Cul4B, an essential Cdt1 ligase, should contribute to Cdt1 stabilization, it is also possible that attenuation of Cdt1 proteolysis might reflect a more direct mechanism resulting from D1T286A/ CDK4-mediated phosphorylation. However, while recent work suggested that CDK4 can phosphorylate Cdt1 in vitro (Liu et al. 2004), we have been unable to establish Cdt1 as a bona fide cyclin D1/CDK4 substrate in vitro or in vivo.

Proteasome-resistant cyclin E can also trigger genomic instability (Spruck et al. 1999; Loeb et al. 2005; Tort et al. 2006). As cyclin E functions downstream from cyclin D1, the affects of D1T286A on DNA replication and genome stability might reflect dysregulation of cyclin E. Several observations do not favor this model. First, in contrast to cyclin D1T286A, which promotes origin licensing and rereplication, the cyclin E/CDK2 kinase is proposed to trigger premature S-phase entry prior to complete origin establishment (Spruck et al. 1999; Loeb et al. 2005; Tort et al. 2006). Second, if overactivation of cyclin E was the primary contributor, then both wild-type cyclin D1 and D1T286A should promote similar phenotypes, since both phosphorylated $\mathrm{Rb}$ during G1. Third, total CDK2 activity is not increased in D1T286A-expressing cells (data not shown). Finally, CDK2 activity triggers Cdt1 proteolysis, through the Skp2 E3 ligase (Liu et al. 2004; Sugimoto et al. 2004; Takeda et al. 2005; Hu and Xiong 2006). The ability of D1T286A to promote Cdt1 stabilization and therefore oppose CDK2-dependent effects on Cdt1 demonstrates that D1T286A functions in a cyclin E/CDK2-independent manner.

\section{D1T286A-dependent tumorigenesis and genomic instability}

The involvement of cyclin D1 in cancer is not restricted to simple overexpression. Cyclin D1 is subject to point mutations, in-frame deletions, and cancer-specific alternative splicing in various human malignancies (Lu et al. 2003; Moreno-Bueno et al. 2003; Solomon et al. 2003; Benzeno et al. 2006). These gene-specific alterations inhibit phosphorylation of cyclin D1 at Thr286 and 
thereby inhibit both cyclin D1 nuclear export (Alt et al. 2000) and cyclin D1 proteolysis, which occurs in the cytoplasm (Lin et al. 2006). Thus, such mutations trigger both the cyclin D1 overexpression and nuclear retention during $\mathrm{S}$ phase of the cell cycle. Functional inactivation of cyclin nuclear export and proteolysis in cancer implies a critical role for this event in the maintenance of normal cellular proliferation and provides clues important for elucidation of mechanisms whereby the cyclin D1 kinase drives neoplasia.

Genomic instability is a hallmark of human cancer. While the distinction between the contribution of genomic instability to cancer initiation versus tumor heterogeneity remains controversial, activation of the DNA damage checkpoint signaling pathway in preneoplastic tissue is consistent with the former (Bartkova et al. 2005; Gorgoulis et al. 2005) and suggests that initial "hits" trigger DNA damage and p53-dependent apoptosis to counter accumulation of damaged cells. Chronic checkpoint signaling may in turn provide selective pressure for loss of p53. The ability of nuclear D1T286A, but not wild-type cyclin D1, to inhibit Cdt1 proteolysis and promote rereplication is consistent with previously published work revealing that overexpressed wild-type cyclin D1 does not elicit a DNA damage response (Spruck et al. 1999; Tort et al. 2006). We suggest that D1T286Adependent rereplication contributes to neoplasia through at least two direct mechanisms. The first is a strong selective pressure for loss of p53. Second, rereplication results in DNA damage (Vaziri et al. 2003; Davidson et al. 2006) that in turn contributes to an increased frequency of oncogenic mutations and tumor heterogeneity (e.g., genomic instability).

The reduced expression of $\mathrm{Cul} 4$ in tumors arising in the E $\mu$-D1T286A mice prompted us to begin evaluating expression of Cul4A in primary esophageal carcinoma, a cancer wherein a oncogenic splice variant of cyclin D1 is frequently expressed (Lu et al. 2003). We predicted that accumulation of this nuclear variant, cyclin D1b, should correlate with decreased Cul4 expression and induction of $\gamma \mathrm{H} 2 \mathrm{AX}$. Our analysis using a tumor tissue array revealed a strong positive correlation, with a majority of tumors positive for cyclin D1b exhibiting $\gamma \mathrm{H} 2 \mathrm{AX}$ staining and reduced Cul4A levels. Thus far, we have been unable to evaluate either Cdt1 or Cul4B as the available antisera were unsuitable for IHC analysis.

Although cyclin D1 can act as an initiating event for cancer development, cyclin D1 also functions in downstream pathways triggered by oncogenes such as Ras and Her2/Neu. Recent data reveal that formation of active cyclin D1/CDK4 kinase is critical for Neu-dependent tumorigenesis (Landis et al. 2006; Yu et al. 2006). It is assumed that in this context, cyclin D1 function pertains to inactivation of $\mathrm{Rb}$ and titration of $\mathrm{CDK}$ inhibitors. However, given that growth factor signals down-regulate cyclin D1 phosphorylation, leading to its nuclear retention, it is conceivable that oncogenic signals might also contribute to aneuploidy and genomic instability through their capacity to promote nuclear accumulation of the cyclin D1 kinase during $\mathrm{S}$ phase.

\section{Materials and methods}

\section{Animal husbandry}

Eu-D1T286A transgenic mice were described previously (Gladden et al. 2006). p53 ${ }^{-1-}$ mice were obtained from Jax Laboratory. Mice were maintained in animal facilities in the University of Pennsylvania, and protocols were approved by the Institutional Animal Care and Use Committees (IACUC) of the University of Pennsylvania.

\section{Antibodies}

For IHC, flow cytometry, and immunoblot analysis, the primary antibodies used include cyclin D1 (D1-17-13G), Ki-67 (ab833500), and phospho-Chk2 (Thr68)(ab38461) (Abcam); CD3 (1452C11), B220 (RA3-6B2), CD19 (1D3), IgM (R6-60.2), IgD (1126c.2a), and GFP (JL-8) (BD Biosciences); phospho-p53 (Ser15), phospho-ATM (Ser1981) (10H11.E12), p-histone H3 (6G3), and $\gamma \mathrm{H} 2 \mathrm{AX}$ (Ser139) (Cell Signaling); Chk2 (Transduction Laboratories, clone 19); ATM (Serotec, AHP392); $\beta$ Actin (Sigma, AC-15); c-myc (9E10), CDK4 (C-22 or H-22), cyclin A (C-19), MCM3 (N-19), Skp2 (H-435), and Cul4B (H-66) (Santa Cruz Biotechnologies); rabbit anti-human Cdt1 (BWH131, UVA249, or UVA250) (Anindya Dutta, UVA); Cul4A (Bethyl Laboratory, Inc); and MCM7 (U.S. Biological, C2563). Antibody binding was visualized using anti-mouse IgG-HRP-linked and anti-rabbit IgG-HRP-linked antibodies (Cell Signaling).

\section{Cell culture}

Splenic cells from wild-type or transgenic mice were extracted by disassociation of the spleen in cold serum-deficient RPMI1640 (GIBCO). Cells were washed in PBS/2\% fetal bovine serum (FBS); were either used for flow cytometry analysis or cultured in RPMI1640, 2 mM L-glutamine (Cellgro), antibiotics (Cellgro), and 10\% heat-inactivated FBS (Gemini Bioproducts); and were stimulated with indicated concentrations of Lipopolysaccharide, $20 \mu \mathrm{g} / \mathrm{mL}$ (Sigma) for $24 \mathrm{~h}$ prior to processing for SKY or Western analysis. U2OS, NIH-3T3, and derivatives were grown in DMEM (GIBCO) supplemented with $2 \mathrm{mM}$ L-glutamine, 10\% FBS, and antibiotics. HeLa cells were grown in MEM (Eagle) (GIBCO) supplemented with $2 \mathrm{mM}$ L-glutamine and Earle's BSS adjusted to contain $1.5 \mathrm{~g} / \mathrm{L}$ sodium bicarbonate, $0.1 \mathrm{mM}$ nonessential amino acids (GIBCO), $1 \mathrm{mM}$ sodium pyruvate (BioWhittaker), and 10\% FBS. H1299, TE3, TE7, and KYSE-520 were grown in RPMI1640 supplemented with $2 \mathrm{mM}$ L-glutamine, $10 \%$ FBS, and antibiotics. Transient transfections were performed following the manufacturer's recommendations using Lipofectamine Plus (Invitrogen).

\section{Genomic instability assays}

Single-cell suspensions stimulated with LPS for $24 \mathrm{~h}$ were treated with Colcemid (GIBCO-BRL; KaryoMAX Colcemid solution; $100 \mathrm{ng} / \mathrm{mL}$ ). For chromosome quantification, chromosomes were stained with Giemsa/DAPI. One-hundred to 200 metaphase spreads were counted for each genotype from multiple mice. For SKY, metaphase spreads were hybridized using a mouse SkyPaint DNA Kit (Applied Spectral Imaging), following the manufacturer's instructions. Five metaphase spreads for each mouse and five mice for each genotype were analyzed by SKY.

Preparation of whole-cell, histone, and chromatin extracts

Protein lysates were prepared from tumor tissue by dissociation as described previously (Gladden et al. 2006). Lysis of U2OS, 
HeLa, TE3, TE7, or KYSE520 cells, transfected/untransfected cells was performed in EBC buffer (Gladden et al. 2006). Histone preparations from mouse splenocytes were made as described previously by Rogakou et al. (1998). Soluble and chromatin fractions were prepared as described previously (Gladden and Diehl 2003).

IHC

Tissue was fixed in $10 \%$ buffered formalin, dehydrated, paraffinembedded, and sectioned. Antigen retrieval was performed using vector antigen unmasking solution followed by blocking of endogenous peroxidase activity by treating with $1 \%$ peroxide for $15 \mathrm{~min}$. Sections were incubated in Power Block (Biogenex) followed by incubation with the primary antibody. Sections were washed with PBS and incubated with a secondary biotinconjugated antibody (Vector Laboratories), washed again, and incubated with $\mathrm{ABC}$ reagent (Vector Laboratories) followed by detection with DAB substrate (Vector Laboratories). The labeling index of individual markers-defined as the percentage of tumor cells displaying nuclear phosho-ATM, phospho-Chk2, and $\gamma \mathrm{H} 2 \mathrm{AX}-$ was determined from random areas of the slide ( $\geq 1000$ tumor cells on each section). Slides were scored doubleblind with satisfactory concordance between two persons. TUNEL analysis on the paraffin-embedded tissue sections was performed according to the manufacturer's suggested protocol (Roche).

\section{Real-time quantitative PCR analysis of gene expression}

RNA isolation was performed using standard protocols. cDNA was prepared by RT-PCR (SuperScript, Invitrogen). Mixed primer/probe sets for Cdt1, Cul4A, Cul4B, Cdt2, $\beta$-actin, and $18 \mathrm{~S}$ rRNA were used to measure the levels of these transcripts using the Applied Biosystems $7900 \mathrm{HT}$ sequence detection system according to the manufacturer's instructions. Primers used for detection of murine Cdt1 were forward, 5'-TGTTCAGGA GATGATGCGCA- ${ }^{\prime}$; and reverse, $5^{\prime}$-TGATGCTGTCCTTGA AGGTGG-3'. Primers used for detection of murine Cul4A were forward, 5'-AGCACTGGAGCGAGTACATCAA-3'; and reverse, 5'-CACGTGGTCCACTTTGTCCTT-3'. Primers used for detection of human Cul4A were forward, 5'-TTCCAGAA GAATGAGCGGTTCG-3'; and reverse, $5^{\prime}$-TCTGTGGCTTCT TTGTTGCCTG-3'. Primers for human cul4B were forward, 5' GCGAAGATCACATCAAAGCACA-3'; and reverse, 5'-AGTC CCATGTCCCAAATGGAG-3'. Primers for murine cul4B were forward, 5'-AAGGTCTCTGATTCATGAGCCA-3'; and reverse, 5'GCGCTCTTGATTGGAGGTTT-3'. Primers for human CDT2 were forward, 5'-CAGCAGGTGATCAAACAG CCA-3'; and reverse, 5'-CCATCTCTTCCACCCGTACAGA3'. Primers for murine CDT2 were forward, 5'-TCGACAA GAACCCATAGCATCC-3'; and reverse, 5'-GCCACCGGAGA AGTCTTTAAGC-3'.

\section{Flow cytometry}

For cell surface marker analysis, the specified tissues were dissociated and washed in PBS containing $2 \%$ fetal calf serum (FCS). Staining was performed in PBS/2\% FCS using antibodies specific for B220-PerCP, CD19-APC, IgM-PE, and IgD-FITC. For DNA analysis, lymphoid cells were washed in PBS and stained with propidium iodide. For analysis of $>4 \mathrm{~N}$ DNA content, cells were harvested, fixed with ethanol, and stained with propidium iodide staining buffer. For BrdU-PI analysis, cells were harvested, fixed, and stained as described previously (Zhang et al. 2006).

\section{Statistical analysis}

All data are shown as means \pm S.D. The Student's t-test was used to compare various experimental groups. Overall survival was measured using the Kaplan-Meier method, and the log-rank test was used for group comparison. Significance was set at $P<0.05$.

\section{Acknowledgments}

We thank A. Dutta for providing the Cdt1 antisera and cDNA, P. Zhou for the Cul4A cDNA, and J.W. Harper for the Cul4B and Cdt2 cDNAs. We also thank Dr. E. Brown for critical insight regarding this work. This work was supported by grants from the NIH (CA93237) and a Leukemia and Lymphoma Scholar award (to J.A.D.), P01-CA098101 (to A.R.), and a grant from the W.W. Smith Charitable Trust and the Pew foundation (to C.H.B.).

\section{References}

Aktas, H., Cai, H., and Cooper, G.M. 1997. Ras links growth factor signaling to the cell cycle machinery via regulation of cyclin D1 and the Cdk inhibitor p27KIP1. Mol. Cell. Biol. 17: 3850-3857.

Albanese, C., Johnson, J., Watanabe, G., Eklund, N., Vu, D., Arnold, A., and Pestell, R.G. 1995. Transforming p21ras mutants and c-Ets-2 activate the cyclin D1 promoter through distinguishable regions. J. Biol. Chem. 270: 23589-23597.

Alt, J.R., Cleveland, J.L., Hannink, M., and Diehl, J.A. 2000. Phosphorylation-dependent regulation of cyclin D1 nuclear export and cyclin D1-dependent cellular transformation. Genes \& Dev. 14: 3102-3114.

Bani-Hani, K., Martin, I.G., Hardie, L.J., Mapstone, N., Briggs, J.A., Forman, D., and Wild, C.P. 2000. Prospective study of cyclin D1 overexpression in Barrett's esophagus: Association with increased risk of adenocarcinoma. J. Natl. Cancer Inst. 92: 1316-1321.

Barnes, D.M. and Gillett, C.E. 1998. Cyclin D1 in breast cancer. Breast Cancer Res. Treat. 52: 1-15.

Bartkova, J., Lukas, J., Muller, H., Lutzhoft, D., Strauss, M., and Bartek, J. 1994a. Cyclin D1 protein expression and function in human breast cancer. Int. J. Cancer 57: 353-361.

Bartkova, J., Lukas, J., Strauss, M., and Bartek, J. 1994b. The PRAD-1/cyclin D1 oncogene product accumulates aberrantly in a subset of colorectal carcinomas. Int. J. Cancer 58: 568-573.

Bartkova, J., Lukas, J., Muller, H., Strauss, M., Gusterson, B., and Bartek, J. 1995. Abnormal patterns of D-type cyclin expression and G1 regulation in human head and neck cancer. Cancer Res. 55: 949-956.

Bartkova, J.H.Z., Koed, K., Kramer, A., Tort, F., Zieger, K., Guldberg, P., Sehested, M., Nesland, J.M., Lukas, C., Orntoft, T., et al. 2005. DNA damage response as a candidate anti-cancer barrier in early human tumorigenesis. Nature 434: 864-870.

Bartkova, J., Rezaei, N., Liontos, M., Karakaidos, P., Kletsas, D., Issaeva, N., Vassiliou, L.V., Kolettas, E., Niforou, K., Zoumpourlis, V.C., et al. 2006. Oncogene-induced senescence is part of the tumorigenesis barrier imposed by DNA damage checkpoints. Nature 444: 633-637.

Bell, S.P. and Dutta, A. 2002. DNA replication in eukaryotic cells. Annu. Rev. Biochem. 71: 333-374.

Benzeno, S., Lu, F., Guo, M., Barbash, O., Zhang, F., Herman, J.G., Klein, P.S., Rustgi, A., and Diehl, J.A. 2006. Identification of mutations that disrupt phosphorylation-dependent 
nuclear export of cyclin D1. Oncogene 25: 6291-6303.

Bodrug, S.E., Warner, B.J., Bath, M.L., Lindeman, G.J., Harris, A.W., and Adams, J.M. 1994. Cyclin D1 transgene impedes lymphocyte maturation and collaborates in lymphomagenesis with the myc gene. EMBO J. 13: 2124-2130.

Cheng, M., Sexl, V., Sherr, C.J., and Roussel, M.F. 1998. Assembly of cyclin D-dependent kinase and titration of p27Kip1 regulated by mitogen-activated protein kinase kinase (MEK1). Proc. Natl. Acad. Sci. 95: 1091-1096.

Davidson, I.F., Li, A., and Blow, J.J. 2006. Deregulated replication licensing causes DNA fragmentation consistent with head-to-tail fork collision. Mol. Cell 24: 433-443.

Di Micco, R., Fumagalli, M., Cicalese, A., Piccinin, S., Gasparini, P., Luise, C., Schurra, C., Garre, M., Nuciforo, P.G., Bensimon, A., et al. 2006. Oncogene-induced senescence is a DNA damage response triggered by DNA hyper-replication. Nature 444: 638-642.

Diehl, J.A., Cheng, M., Roussel, M.F., and Sherr, C.J. 1998. Glycogen synthase kinase- $3 \beta$ regulates cyclin D1 proteolysis and subcellular localization. Genes \& Dev. 12: 3499-3511.

Ewen, M.E. and Lamb, J. 2004. The activities of cyclin D1 that drive tumorigenesis. Trends Mol. Med. 10: 158-162.

Franke, T.F., Yang, S.I., Chan, T.O., Datta, K., Kazlauskas, A., Morrison, D.K., Kaplan, D.R., and Tsichlis, P.N. 1995. The protein kinase encoded by the Akt proto-oncogene is a target of the PDGF-activated phosphatidylinositol 3-kinase. Cell 81: 727-736.

Franke, T.F., Kaplan, D.R., Cantley, L.C., and Toker, A. 1997. Direct regulation of the Akt proto-oncogene product by phosphatidylinositol-3,4-bisphosphate. Science 275: 665-668.

Gillett, C., Fantl, V., Smith, R., Fisher, C., Bartek, J., Dickson, C., Barnes, D., and Peters, G. 1994. Amplification and overexpression of cyclin D1 in breast cancer detected by immunohistochemical staining. Cancer Res. 54: 1812-1817.

Gladden, A.B. and Diehl, J.A. 2003. The cyclin D1-dependent kinase associates with the pre-replication complex and modulates RB.MCM7 binding. J. Biol. Chem. 278: 9754-9760.

Gladden, A.B. and Diehl, J.A. 2005. Location, location, location: The role of cyclin D1 nuclear localization in cancer. J. Cell. Biochem. 96: 906-913.

Gladden, A.B., Woolery, R., Aggarwal, P., Wasik, M.A., and Diehl, J.A. 2006. Expression of constitutively nuclear cyclin D1 in murine lymphocytes induces B-cell lymphoma. Oncogene 25: 998-1007.

Gorgoulis, V.G., Vassiliou, L.V., Karakaidos, P., Zacharatos, P., Kotsinas, A., Liloglou, T., Venere, M., Ditullio Jr., R.A., Kastrinakas, N.G., Levy, B., et al. 2005. Activation of the DNA damage checkpoint and genomic instability in human precancerous lesions. Nature 434: 907-913.

Hemmer, S., Wasenius, V.M., Haglund, C., Zhu, Y., Knuutila, S., Franssila, K., and Joensuu, H. 2001. Deletion of 11q23 and cyclin D1 overexpression are frequent aberrations in parathyroid adenomas. Am. J. Pathol. 158: 1355-1362.

Herman, J.G., Merlo, A., Mao, L., Lapidus, R.G., Issa, J.P., Davidson, N.E., Sidransky, D., and Baylin, S.B. 1995. Inactivation of the CDKN2/p16/MTS1 gene is frequently associated with aberrant DNA methylation in all common human cancers. Cancer Res. 55: 4525-4530.

Hibberts, N.A., Simpson, D.J., Bicknell, J.E., Broome, J.C., Hoban, P.R., Clayton, R.N., and Farrell, W.E. 1999. Analysis of cyclin D1 (CCND1) allelic imbalance and overexpression in sporadic human pituitary tumors. Clin. Cancer Res. 5: 21332139.

Higa, L.A., Wu, M., Ye, T., Kobayashi, R., Sun, H., and Zhang, H. 2006. CUL4-DDB1 ubiquitin ligase interacts with mul- tiple WD40-repeat proteins and regulates histone methylation. Nat. Cell Biol. 8: 1277-1283.

Hoglund, P. 2006. DNA damage and tumor surveillance: One trigger for two pathways. Sci. STKE 2006: pe2. doi: 10.1126/ stke.3172006pe2.

Hosokawa, Y., Joh, T., Maeda, Y., Arnold, A., and Seto, M. 1999. Cyclin D1/PRAD1/BCL-1 alternative transcript [B] protein product in B-lymphoid malignancies with $\mathrm{t}(11 ; 14)(\mathrm{q} 13 ; \mathrm{q} 32)$ translocation. Int. J. Cancer 81: 616-619.

$\mathrm{Hu}, \mathrm{J}$. and Xiong, Y. 2006. An evolutionarily conserved function of proliferating cell nuclear antigen for Cdt1 degradation by the Cul4-Ddb1 ubiquitin ligase in response to DNA damage. J. Biol. Chem. 281: 3753-3756.

Ikeguchi, M., Sakatani, T., Ueta, T., and Kaibara, N. 2001. Cyclin D1 expression and retinoblastoma gene protein $(\mathrm{pRB})$ expression in esophageal squamous cell carcinoma. J. Cancer Res. Clin. Oncol. 127: 531-536.

Jin, M., Inoue, S., Umemura, T., Moriya, J., Arakawa, M., Nagashima, K., and Kato, H. 2001. Cyclin D1, p16 and retinoblastoma gene product expression as a predictor for prognosis in non-small cell lung cancer at stages I and II. Lung Cancer 34: 207-218.

Jin, J., Arias, E.E., Chen, J., Harper, J.W., and Walter, J.C. 2006. A family of diverse Cul4-Ddb1-interacting proteins includes $\mathrm{Cdt} 2$, which is required for S phase destruction of the replication factor Cdt1. Mol. Cell 23: 709-721.

Kastan, M.B. and Bartek, J. 2004. Cell-cycle checkpoints and cancer. Nature 432: 316-323.

Landis, M.W., Pawlyk, B.S., Li, T., Sicinski, P., and Hinds, P.W. 2006. Cyclin D1-dependent kinase activity in murine development and mammary tumorigenesis. Cancer Cell 9: 13-22.

Lavoie, J.N., L'Allemain, G., Brunet, A., Muller, R., and Pouyssegur, J. 1996. Cyclin D1 expression is regulated positively by the p42/p44MAPK and negatively by the p38/HOGMAPK pathway. J. Biol. Chem. 271: 20608-20616.

Lin, D.I., Barbash, O., Kumar, K.G., Weber, J.D., Harper, J.W., Klein-Szanto, A.J., Rustgi, A., Fuchs, S.Y., and Diehl, J.A. 2006. Phosphorylation-dependent ubiquitination of cyclin D1 by the SCF(FBX4- $\alpha$ B crystallin) complex. Mol. Cell 24: 355-366.

Liu, E., Li, X., Yan, F., Zhao, Q., and Wu, X. 2004. Cyclindependent kinases phosphorylate human Cdt1 and induce its degradation. J. Biol. Chem. 279: 17283-17288.

Loeb, K.R., Kostner, H., Firpo, E., Norwood, T., Tsuchiva, K.D., Clurman, B.E., and Roberts, J.M. 2005. A mouse model for cyclin E-dependent genetic instability and tumorigenesis. Cancer Cell 8: 35-47.

Lovec, H., Grzeschiczek, A., Kowalski, M.B., and Moroy, T. 1994. Cyclin D1/bcl-1 cooperates with myc genes in the generation of B-cell lymphoma in transgenic mice. $E M B O J$. 13: 3487-3495.

Lu, F., Gladden, A.B., and Diehl, J.A. 2003. An alternatively spliced cyclin D1 isoform, cyclin D1b, is a nuclear oncogene. Cancer Res. 63: 7056-7061.

Marshall, C. 1999. How do small GTPase signal transduction pathways regulate cell cycle entry? Curr. Opin. Cell Biol. 11: 732-736.

Moreno-Bueno, G., Rodriguez-Perales, S., Sanchez-Estevez, C., Hardisson, D., Sarrio, D., Prat, J., Cigudosa, J.C., MatiasGuiu, X., and Palacios, J. 2003. Cyclin D1 gene (CCND1) mutations in endometrial cancer. Oncogene 22: 6115-6118.

Nishitani, H., Sugimoto, N., Roukos, V., Nakanishi, Y., Saijo, M., Obuse, C., Tsurimoto, T., Nakayama, K.I., Nakayama, K., Fujita, M., et al. 2006. Two E3 ubiquitin ligases, SCFSkp2 and DDB1-Cul4, target human Cdt1 for proteolysis. EMBO I. 25: 1126-1136. 
Opitz, O.G., Suliman, Y., Hahn, W.C., Harada, H., Blum, H.E., and Rustgi, A.K. 2001. Cyclin D1 overexpression and p53 inactivation immortalize primary oral keratinocytes by a telomerase-independent mechanism. J. Clin. Invest. 108: 725-732.

Rajagopalan, H. and Lengauer, C. 2004. Aneuploidy and cancer. Nature 432: 338-341.

Rogakou, E.P., Pilch, D.R., Orr, A.H., Ivanova, V.S., and Bonner, W.M. 1998. DNA double-stranded breaks induce histone H2AX phosphorylation on serine 139. J. Biol. Chem. 273: 5858-5868.

Sansam, C.L., Shepard, J.L., Lai, K., Ianari, A., Danielian, P.S. Amsterdam, A., Hopkins, N., and Lees, J.A. 2006. DTL/ CDT2 is essential for both CDT1regulation and the early G2/M checkpoint. Genes \& Dev. 20: 3117-3129.

Sherr, C.J. 1996. Cancer cell cycles. Science 274: 1672-1677.

Sherr, C.J. 1998. Tumor surveillance via the ARF-p53 pathway. Genes \& Dev. 12: 2984-2991.

Solomon, D.A., Wang, Y., Fox, S.R., Lambeck, T.C., Giesting, S., Lan, Z., Senderowicz, A.M., and Knudsen, E.S. 2003. Cyclin D1 splice variants. Differential effects on localization, RB phosphorylation, and cellular transformation. J. Biol. Chem. 278: 30339-30347.

Spruck, C.H., Won, K.A., and Reed, S.I. 1999. Deregulated cyclin E induces chromosome instability. Nature 401: 297-300.

Sugimoto, N., Tatsumi, Y., Tsurumi, T., Matsukage, A., Kiyono, T., Nishitani, H., and Fujita, M. 2004. Cdt1 phosphorylation by cyclin A-dependent kinases negatively regulates its function without affecting geminin binding. J. Biol. Chem. 279: 19691-19697.

Takeda, D.Y., Parvin, J.D., and Dutta, A. 2005. Degradation of Cdt1 during S phase is Skp2-independent and is required for efficient progression of mammalian cells through $S$ phase. $J$. Biol. Chem. 280: 23416-23423.

Tort, F., Bartkova, J., Sehested, M., Orntoft, T., Lukas, J., and Bartek, J. 2006. Retinoblastoma pathway defects show differential ability to activate the constitutive DNA damage response in human tumorigenesis. Cancer Res. 66: 1025810263.

van den Heuvel, S. and Harlow, E. 1993. Distinct roles for cyclin-dependent kinases in cell cycle control. Science 262: 2050-2054.

Vaziri, C., Saxena, S., Jeon, Y., Lee, C., Murata, K., Machida, Y., Wagle, N., Hwang, D.S., and Dutta, A. 2003. A p53-dependent checkpoint pathway prevents rereplication. Mol. Cell 11: 997-1008.

Yu, Q., Sicinska, E., Geng, Y., Ahnstrom, M., Zagozdzon, A., Kong, Y., Gardner, H., Kiyokawa, H., Harris, L.N., Stal, O., et al. 2006. Requirement for CDK4 kinase function in breast cancer. Cancer Cell 9: 23-32.

Zhang, F., Hamanaka, R.B., Bobrovnikova-Marjon, E., Gordan, J.D., Dai, M.S., Lu, H., Simon, M.C., and Diehl, J.A. 2006. Ribosomal stress couples the unfolded protein response to p53-dependent cell cycle arrest. J. Biol. Chem. 281: $30036-$ 30045. 


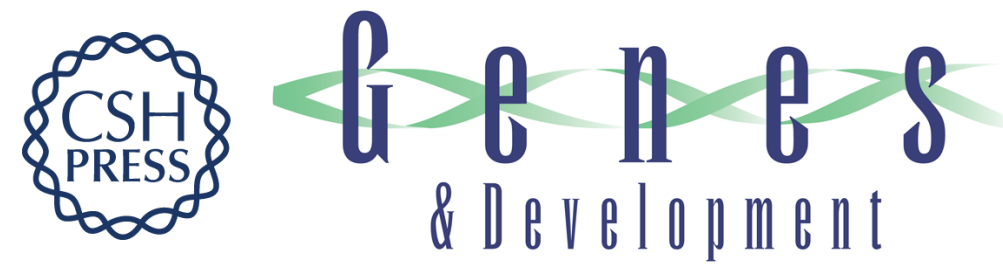

\section{Nuclear accumulation of cyclin D1 during $S$ phase inhibits Cul4-dependent Cdt1 proteolysis and triggers p53-dependent DNA rereplication}

Priya Aggarwal, Matthew D. Lessie, Douglas I. Lin, et al.

Genes Dev. 2007, 21:

Access the most recent version at doi:10.1101/gad.1586007

Supplemental Material

References License

Email Alerting Service
http://genesdev.cshlp.org/content/suppl/2007/11/01/21.22.2908.DC1

This article cites 61 articles, 26 of which can be accessed free at: http://genesdev.cshlp.org/content/21/22/2908.full.html\#ref-list-1

Receive free email alerts when new articles cite this article - sign up in the box at the top right corner of the article or click here. 